\title{
Role of ESR Pathway Genes in Breast Cancer: A Review
}

\author{
Deepak Kumar ${ }^{1 *}$, Marilyn Rae Myers², Ussama Al Homsi³ ${ }^{3}$ Valentin Ilyin ${ }^{1}$ \\ ${ }^{1}$ Computational Biology, Carnegie Mellon University in Qatar (CMU-Q), Doha, Qatar \\ ${ }^{2}$ Pennsylvania State University, University Park, USA \\ ${ }^{3}$ Hematology and Oncology Department, NCCCR, Hamad Medical Corporation, Doha, Qatar \\ Email:*deepakk1@andrew.cmu.edu, vilyin@andrew.cmu.edu
}

How to cite this paper: Kumar, D., Myers, M.R., Al Homsi, U. and Ilyin, V. (2018) Role of ESR Pathway Genes in Breast Cancer: A Review. Advances in Breast Cancer Research, 7, 134-186.

https://doi.org/10.4236/abcr.2018.72010

Received: March 20, 2018

Accepted: April 27, 2018

Published: April 30, 2018

Copyright $\odot 2018$ by authors and Scientific Research Publishing Inc. This work is licensed under the Creative Commons Attribution International License (CC BY 4.0).

http://creativecommons.org/licenses/by/4.0/

(c) (i) Open Access

\begin{abstract}
Breast cancer is the leading cause of death in women. Prognosis of breast cancer is often pessimistic because the tumors are prone to metastasizing to the bone, brain, and lung. The estrogen signaling receptor (ESR) pathway contains 39 main genes and proteins which makes it one of the larger signaling pathways. Predominately this pathway and the proteins within are involved in breast growth and development, making it a prospective area of study for breast cancer. While the healthy ESR pathway has been constructed and is well established, a mechanistic model of mutated genes of ESR pathway has not been delved upon. Such mutated models could be utilized for selecting combinational targets for drug therapies, as well as elucidating crosstalk between other pathways and feedback mechanisms. To construct the mutated models of the ESR pathway it is imperative to assess what is currently understood in the literature and what inconsistencies exist in order to resolve them. Without this information, a model of the ESR pathway will be unreliable and likely unproductive. This review is the detailed literature survey of the biological studies performed on ESR pathways genes, and their respective roles in breast cancer. Furthermore, the details mentioned in the review can be beneficial for the integrated study of the ESR pathway genes, which includes, structural and dynamics study of the genes products, to have a holistic understanding of the cancer mechanism.
\end{abstract}

\section{Keywords}

Estrogen Signaling Receptor (ESR) Pathway, Breast Cancer, ESR Genes, Mechanistic Modeling, Integrated Study, Kyoto Encyclopedia of Genes and Genomes (KEGG), PubMed, Literature Survey 


\section{Introduction}

Breast cancer is an aggressive and invasive disease that produces a malig-nant tumor due to multiple mutations in the genome. It is known that breast cancer is the leading cause of mortality and morbidity in women by cancer worldwide, although in some rare cases the disease has been diagnosed in male patients. In 2016 , it is estimated that there will be 246,660 new cases of invasive breast cancer and 40,450 deaths attributed to breast cancer in the United States [1]. Additionally, it is alarming to observe that the incidence rate has been rising in many countries [2]. A major factor in breast cancer fatality is that the disease frequently metastasizes and invades multiple regions in the body, including the bone, lung, and brain. Consequently, it is pertinent to research how breast cancer develops in order to design an appropriate method of treatment.

To develop such a treatment, it is critical to have a comprehensive understanding of the mutated genes that cause breast cancer and the mechanistic changes that occur. Whereas there is much research on individual genes and smaller cascade models, there has been little done to obtain a more holis-tic comprehension of these effects. In order to facilitate the development of mutated pathway models, it is the aim of this report to compile and incorporate sources of research to be used for designing this larger pathway model. However, it must be noted that although this would be a useful endeavor it would not be specific to individuals. This is a significant distinction as there are multiple subtypes of breast cancer often containing different mutations which subsequently can cause varied reactions to specific treatments. While it would be advantageous to do this for all pathways that are known to mutate in the development of breast cancer, this report will specifically look at the estrogen signaling receptor (ESR) pathway, using the Kyoto Encyclopedia of Genes and Genomes (KEGG) ESR pathway as reference (Figure 1).

The ESR pathway is a prospective starting point to unravel the mechanisms of breast cancer. Estrogen, an integral component of the ESR pathway, is a steroidal hormone which is involved in multiple functions including the development and maturation of breasts. Due to its involvement in the growth of breasts it is a likely candidate in providing information regarding tumor formation. Consequently, study of the major ESR pathway estrogen is involved in, will improve our comprehension of the breast tumor development and progression. Research already shows that the ESR pathway is implicated in breast cancer progression, and the majority of human breast cancers start out as estrogen dependent [3]. It is pertinent to develop a model of the mutations that occur in this pathway causing breast cancer. Moreover, the ESR pathway is quite large and involves numerous genes that are involved in multiple pathways besides the ESR. Thus, mutations and changes in the mechanisms of the ESR pathway can have an indirect effect on a multitude of diverse pathways. For instance, Src is involved in both the ESR pathway and the focal adhesion pathway. This demonstrates how multiple pathways are interrelated and emphasizes how critical it is to model the changes of the major mutated pathways. 


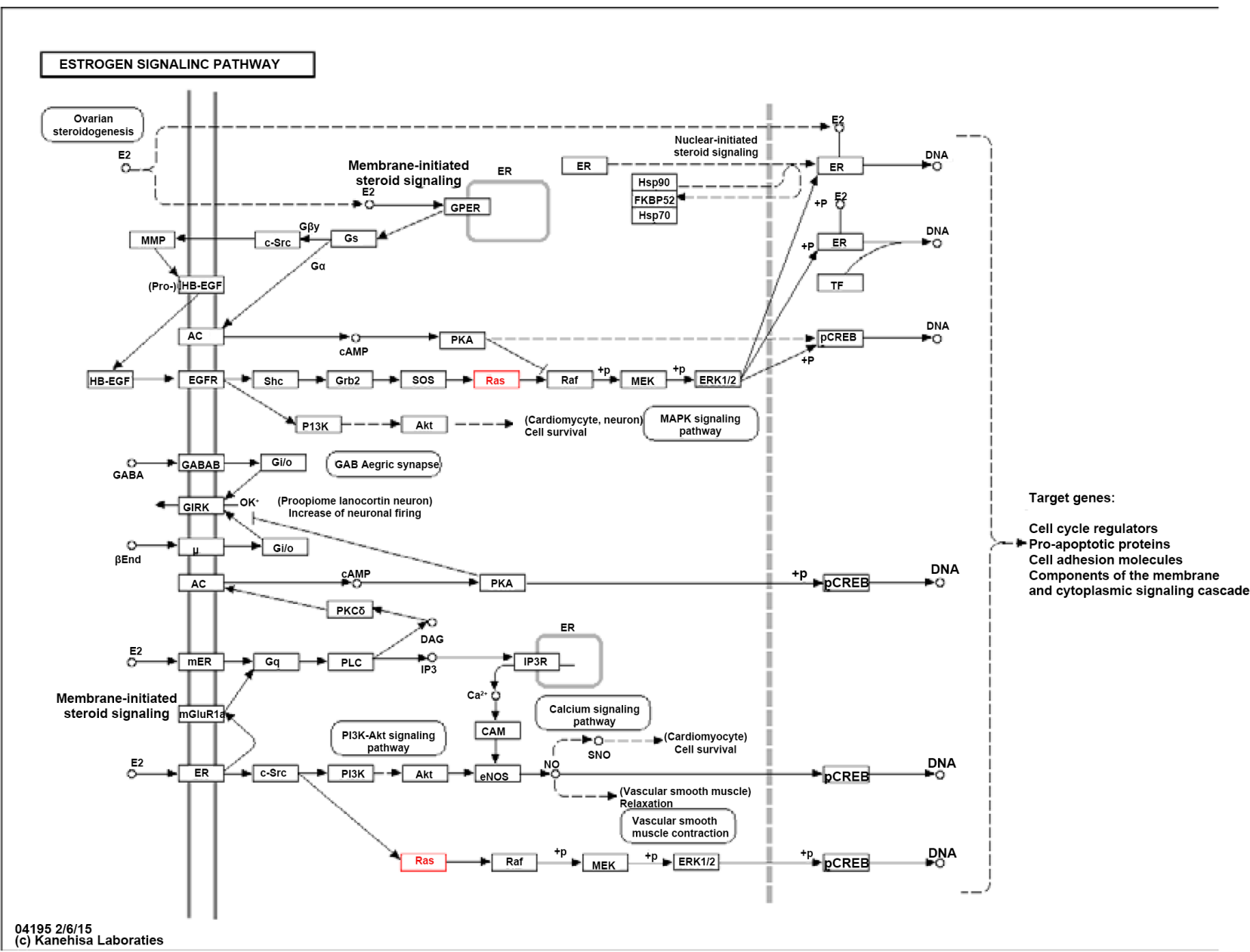

Figure 1. Representation of the ESR pathway from Kyoto Encyclopedia of Genes and Genomes (KEGG-PATHWAY: map04915).

By collecting information on what is currently known about the proteins and genes involved in the ESR pathway this can direct future studies, such as computational studies involving structural analysis of the molecules. Molecular dynamic studies along with other computational methods could overcome the limitations of crystallography and provide useful structural and functional insights [4]. Such studies can be useful in understanding the network dynam-ics of the genes and protein molecules involved in breast cancer. Moreover, structural level study can provide insight into the architectural and conformational changes of the molecules occurring due to point mutations or single nucleotide polymorphism (SNP). While computational studies have been utilized in many areas of research, there are many avenues in the breast cancer field that could still benefit from such studies. Molecular dynamic studies have already benefitted some research, specifically by revealing a detailed consequence of the mutations on the p53 DNA-binding core domain that may now provide insight for therapeutic approaches in breast cancer [5]. By laying out what is currently ambiguous in terms of the proteins and genes interactions and consequence to tumor formation, this report highlights future avenues of study which could take advantage of aforementioned structural analysis methods. 
In Table 1, depending on the literature study, genes in varied correlation category were found to act as both tumor suppressor and promoter. Genes in the consensus correlation category are the genes that do not deviate from suppressing or promoting tumor progression according to current literature.

\section{Literature Consensus on Correlations to Breast Cancer}

This section contains information on genes where there is agreement across the literature on the correlation the gene has to breast cancer. However, the literature may propose different mechanisms by which the gene induces tumor formation. Overview of all the genes assessed and evaluated is illustrated in Table 2.

\subsection{HBEGF Induces Invadopodia and Metastasis}

Heparin binding EGF like growth factor (HBEGF) can be found either bound to the cell membrane or as a solute in the ECM. Although the molecule must undergo proteolytic cleavage to become a solute in the ECM, the molecule's function

Table 1. Shows whether in current literature a particular gene correlation to breast cancer is agreed upon or whether a gene is observed to act both as a tumor suppressor and promoter, as determined by this review. The genes are from ESR pathway of KEGG (PATHWAY: map04915).

\begin{tabular}{|c|c|}
\hline Varied Correlations & Consensus Correlation \\
\hline $\mathrm{E} 2$ & HBEGF \\
\hline MMP & EGFR \\
\hline GABA & GABAB \\
\hline OPRM1 & GIRK \\
\hline $\mathrm{AC}$ & mGluR \\
\hline Shc & Src \\
\hline cAMP & $\mathrm{G} \alpha$ \\
\hline PI3K & Grb2 \\
\hline PKC & Akt \\
\hline PKA & Ras \\
\hline PLC & sos \\
\hline IP3R & DAG \\
\hline IP3 & CAM \\
\hline eNOS & Raf \\
\hline MAPK & MEK \\
\hline \multirow[t]{4}{*}{ AP1 } & FKBP \\
\hline & NO \\
\hline & CREB \\
\hline & BEP \\
\hline
\end{tabular}


Table 2. Genes and their cognate variants found in the healthy ESR pathway compiled using the ESR reference pathway from Kyoto Encyclopedia of Genes and Genomes (KEGG).

\begin{tabular}{|c|c|}
\hline Genes found in the healthy ESR pathway & $\begin{array}{l}\text { Gene variants involved in the } \\
\text { healthy ESR pathway }\end{array}$ \\
\hline \multicolumn{2}{|l|}{ Estradiol-17 beta (E2) } \\
\hline Matrix metalloproteinase (MMP) & MMP2, MMP9 \\
\hline \multicolumn{2}{|l|}{ Heparin-binding EGF-like growth factor (HBEGF) } \\
\hline \multicolumn{2}{|l|}{ Gamma-aminobutyric acid (GABA) } \\
\hline \multicolumn{2}{|l|}{ Beta-Endorphin ( $\beta$ End) } \\
\hline Adenylate Cyclase (AC) & $\begin{array}{c}\text { ADCY1, ADCY2, ADCY3, ADCY4, } \\
\text { ADCY5, ADCY6, ADCY7, ADCY8, ADCY9 }\end{array}$ \\
\hline \multicolumn{2}{|l|}{ Epidermal growth factor receptor (EGFR) } \\
\hline Gamma-aminobutyric acid B receptor (GABAB) & GABBR \\
\hline GIRK & KCNJ3, KCNJ5, KCNJ6, KCNJ9 \\
\hline \multicolumn{2}{|l|}{ Opioid receptor $\mu$ (OPRM1) } \\
\hline \multicolumn{2}{|l|}{ Membrane estrogen receptor (mER) } \\
\hline Metabotropic glutamate receptors (mGluR1a) & GRM1 \\
\hline Estrogen receptor (ER) & NR3A1, NR3A2 \\
\hline Proto-oncogene, non-receptor tyrosine kinase (c-Src) & Src \\
\hline Tyrosine-protein kinase (Shc) & Shc1, Shc2, Shc3, Shc4 \\
\hline \multicolumn{2}{|l|}{ Cyclic adenosine monophosphate (cAMP) } \\
\hline $\begin{array}{l}\text { Phosphatidylinositol-4,5-bisphosphate 3-kinase } \\
\text { (PI3K) }\end{array}$ & PIK3C, PIK3R \\
\hline $\begin{array}{l}\text { Guanine nucleotide-binding protein } \mathrm{G}(\mathrm{i}) \text { subunit } \\
\text { alpha }(\mathrm{Gi} / \mathrm{o})\end{array}$ & GNAI, GNAO \\
\hline Novel protein kinase $\mathrm{C}$ delta type (PKC delta) & PRKCD \\
\hline Guanine Nucleotide-Binding Protein Alpha-Q (Gq) & GNAQ \\
\hline Adenylate Cyclase-Stimulating G Alpha Protein (Gs) & GNAS \\
\hline \multicolumn{2}{|l|}{$\begin{array}{l}\text { Protein kinase cAMP-activated catalytic subunit alpha } \\
\text { (PKA) }\end{array}$} \\
\hline \multicolumn{2}{|l|}{ Growth factor receptor bound protein 2 (Grb2) } \\
\hline \multicolumn{2}{|l|}{ Rac serine/threonine-protein kinase (Akt) } \\
\hline Phospholipase C (PLC) & PLGB \\
\hline GTPaseHras (Ras) & HRAS, KRAS, NRAS \\
\hline G protein-coupled estrogen receptor (GPER) & GPR30 \\
\hline \multicolumn{2}{|l|}{ Son of Sevenless (SOS) } \\
\hline \multicolumn{2}{|l|}{ Diaclyglycerol (DAG) } \\
\hline Inositol 1,4,5-trisphosphate receptor (IP3R) & ITPR1, ITPR2, ITPR3 \\
\hline Calmodulin (CAM) & CALM \\
\hline Nitric oxide synthase 3 (eNOS) & NOS3 \\
\hline
\end{tabular}




\section{Continued}

$\begin{array}{cc}\begin{array}{c}\text { Raf proto-oncogene serine/threonine-protein kinase } \\ \text { (Raf) }\end{array} & \text { RAF1 } \\ \text { Mitogen-activated protein kinase kinase (MEK) } & \text { MAP2K1, MAP2K2 } \\ \text { D-myo-inositol 1,4,5 triphosphate (IP3) } & \\ \text { FK506 binding protein 4 (FKBP52) } & \text { FKBP4_5 } \\ \text { Mitogen-activated protein kinase (ERK1/2) } & \text { MAPK1_3 } \\ \text { Nitric ocide (NO) } & \\ \text { FBJ murine osteosarcoma viral oncogene homolog } & \text { Fos, Jun, SP1 }\end{array}$

remains unchanged. HBEGF is implicated as a participant in various normal physiological and pathologic processes such as cell attachments, chemotaxis, mitosis, and inhibition of cellular apoptosis [6]. It is a microenvironment organizer which contributes to niches where normal stem and progenitor cells are maintained and released into differentiation and where oncogenic processes take place and keep developing [7]. Most importantly HBEGF is not only observed in breast cancer but in a wide variety of cancers, such as ovarian and gastric cancer. There is little disagreement in the medical community over the expression of HBEGF in breast cancer; however the particular mechanism by which HBEGF acts is still under investigation. One report suggests that its subcellular localization and release of $\mathrm{N}$ - and C-terminal fragments are involved in oncogenic behaviors [8]. Additionally, the report observes that HBEGF is a potent inducer of angiogenesis in vivo. It has been speculated that HBEGF and epidermal growth factor receptors (EGFRs) enhances invadopodia in breast cancer, which then acts as a mechanism for cell autonomous invasion that is mediated by matrix metalloproteinase (MMP) 2 and 9 [9]. This is particularly interesting considering that some reports do not observe MMP 2 in breast cancer samples, and consequently acts as evidence for there to be additional research on MMPs presence in breast cancer and their associations with HBEGF.

\subsection{EGFR Amplified in Triple Negative Breast Cancer}

EGFR comprises of two domains, the extracellular ligand binding domain and the intracellular receptor tyrosine kinase (RTK) domain. When bound to a ligand at the cellular level, the complex can induce cell proliferation but also alter adhesion and motility and prevent apoptosis; at the physiological level, the complex promotes invasion and angiogenesis [10]. EGFR is involved in regulating skin cell and squamous epithelia cell division, making it a prime candidate for drug targets in breast cancer therapy. Although EGFR is a significant molecule in maintaining regular cell proliferation, cell proliferation is controlled by multiple pathways and signals, meaning that drug treatment that target EGFR should be in conjunction with other inhibitors. It is not unexpected that EGFR, one of the initial targets for cancer treatments, is overexpressed in multiple subsets of breast cancer. However, drug treatments targeting EGFR, such as gefiti- 
nib, cetuximab, and lapatinib, are often unsuccessful, and perhaps would be more effective by applying personalized medicine methods in order to predict patients who would most benefit from inhibition of EGFR. Though EGFR overexpression is observed in all subtypes of breast cancer, EGFR is more frequently overexpressed in triple-negative breast cancer (TNBC) and inflammatory breast cancer, which are especially aggressive [11]. Therefore, it can be inferred that personalized medicine could be more efficacious in EGFR treatment since some patients are more likely to have overexpression of EGFR. While EGFR is typically more common in particular subsets of breast cancer, the gene is more likely amplified than mutated. One study reports that out of 47 TNBC tumor samples there were no EGFR mutations but amplification of EGFR was observed in well-characterized TNBCs (up to 92\%) [12]. In addition to being able to predict which patients will respond best to EGFR drug treatments, it is critical to reveal why EGFR treatments are not always effective. There is evidence for significant interactions between EGFR family members and other RTKs, such as the receptors for hepatocyte growth factor and insulin-like growth factor, and it is possible that such alternative signaling pathways are linked to resistance to EGFR-targeted therapies [13]. However, these speculations will require further investigations in order to utilize EGFR treatments appropriately.

\subsection{Tumor Suppressing Qualities of Beta-Endorphin}

$\beta$-Endorphin (BEP) shares the $\mu$-opioid receptor (OPRM) with opium and consequently parallels morphine effects. These effects in clude euphoria through inhibition of stress production, stress behavior, and pain. It has been shown that BEP not only inhibits the stress response of hypothalamicpituitary-adrenal axis through interaction with corticotrophin-releasing hormone neurons in the paraventricular nucleus (PVN), but also inhibits the sympathetic nervous system through innervations of the PVN where these BEP molecules bind to $\delta$ - and $\mu$-opioid receptors to modulate the neuro-transmission in neurons of the autonomic nervous system [14].

Unlike many of the other genes/proteins examined in the ESR pathway, this gene does not seem to be directly related to cell survival or growth which would seem pertinent to cancer cells, however a correlation between the two has been observed. It is now believed that stress can be a detriment to cancer treatments and therefore BEP is an important molecule to examine in cancer therapy. It has been shown that while stress-induced neuroendocrine activation has a negligible impact on growth of the primary breast cancer tumor, it induces a 30-fold increase in metastasis to distant tissues including lymph nodes and lung [15]. Taking this into consideration, it is not unexpected that BEP transplantation, due to its stress-inhibiting qualities, has strongly been linked to the inhibition of tumor progression in breast cancer and lung metastasis of mammary adenocarcinoma cells [16]. This same report speculates that the plausible molecular mechanism by which BEP prevents tumor cell metastasis reduces the pharmacological modification of autonomic function that blocks the innate immune re- 
sponse. However, these results were observed in rats and further research should be conducted on BEP, and clinical trials should observe the effects of BEP in addition to standard treatment.

\subsection{Lack of Contemporary Research on GABAB and GIRK}

Gamma-Aminobutyric Acid type B Receptor (GABAB) is made of two subunits. Both subunits contain a large extracellular $\mathrm{N}$-terminal domain, seven-transmembrane domains, and a short intracellular C-terminal domain. The $\mathrm{C}$-terminal domains of both subunits contain a coiled-coil structure involved in the heterodimerization of GABAB [17]. It is interesting to note that whereas ionotropic GABA receptors are ligand-gated chloride channels that mediate fast GABA response, GABAB, belonging to the $C$ family of G-protein-coupled receptors (GCPRs), mediate slow GABA response by acti-vating G-proteins and their downstream effectors [18]. One of these G-proteins is the G protein-coupled inwardly-rectifying potassium channel (GIRK). Upon activation, by GABA or other neurotransmitters involved in pain transmission such as dopamine, serotonin, and opioids, GIRK induces postsynaptic inhibition [19]. Unlike GIRK, an increasing number of studies have demonstrated the potential roles of the neurotransmitter receptor GABAB as tumor suppressors in various cancers [20]. For instance, in colorectal cancer, upregulation of GABAB significantly inhibits the growth of the tumor by halting cell proliferation [21]. GIRK can induce varied responses, although it is known that GIRKs function is highly susceptible to the concentration of GIRK sub-unit present. Most literature that investigates GIRKs has been obtained using animal models that lack one or two of the GIRK channel subunits and consequently much information about GIRK function and mechanisms is unknown in humans [22].

Although activation of GABAB seems to have tumor suppressing effects in some cancers, there has been little investigation on its presence in breast cancer. One report observes that $\mathrm{GABAB} 1$ expression was significantly higher in malignant tissues than in nonmalignant tissues in ductal breast cancer [23]. Unfortunately, this observation is hardly reliable since this was only observed in 3 out of 6 samples, and consequently to have more accurate and reliable analyses, it is pertinent to study GABAB in more breast cancer samples. While its role in breast cancer is not thoroughly explored, there is information on the mechanism of activation. It is suggested that GABAB agonist-induced conformational changes may lead to a rearrangement of the transmembrane domain heterodimer for signal transduction across the membrane [24]. This particular activation method has not been observed for any other receptor. Further investigations of $\mathrm{GABAB}$ in breast cancer would surely make a large impact on our medical community. One of the issues in constructing a mutated mechanistic model of the ESR pathway is that while GABAB is found in the healthy ESR pathway, its expression levels in breast cancer has not been thoroughly explored using reliable methods. Studying its associations with other proteins in breast cancer may 
also prove to be a fruitful endeavor.

There is even less data on GIRKs involvement in breast cancer. Regardless, GIRK has been observed and analyzed in human breast cancer. Specifically, GIRK variants, GIRK1a, GIRK1c and GIRK1d, were not only overexpressed in some breast cancer cell lines but also increased velocity, motility, and invasion of the cells [25]. However, other sources are outdated and therefore more modern techniques and methods could be utilized and applied to analyze GIRK variants in breast cancer and their mechanisms by which they govern breast cancer cells in humans.

\section{5. mGluRs Mediators of Angiogenesis Causing Tumor Growth}

Metabotropic glutamate receptors (mGluRs) typically bind to glutamate, a nonessential amino acid. However, glutamate can also bind to ionotropic glutamate receptors. The major difference between the two receptors is their mechanism of activation. While ionotropic glutamate receptors are voltage-gated channel that change ion concentration, mGluRs are GPCRs that stimulate second messengers. Not all mGluRs activate the same secondary messengers. However, all mGluR isoforms contain the typical seven transmembrane domains as well as an aminoterminal ligand-binding domain and a carboxy-terminal cytoplasmic domain [26]. In comparison to ionotropic glutamate receptors, many studies indicate that mGluRs are the predominant mediators of glutamatergic signaling in cancer [27]. Moreover, mGluRs have been implicated as novel drivers of oncogenesis in melanoma and other tumor types, with somatic mutations that altered downstream mGluR1 intracellular localization signaling [28] [29].

Unsurprisingly, mGluRs mutations and amplifications have been found in breast cancer. One report found that mGluR1 was present in 5 TNBC cell lines tested and in normal mammary epithelial cells, however their analysis suggested that mGluR1 might be functional in breast cancer cells but not in normal mammary epithelium [30]. Additionally, they observed that the inhibition of mGluR1 induces apoptosis in vivo by xenografts in mice. This concurs with another study which states that mGluR1 activity is increased in breast cancer cell lines, specifically TNBC by promotingmigration and invasion [31]. The same report notes that, consistent with the concept that multiple genetic changes are usually required to transform a normal cell to a malignant phenotype, mGluR1 appears to function in the background of genetic changes that "prime" the cell (in MCF10AT1, c-Ha-ras). This response to the activity of mGluR1 by transformation appears to be a dose requirement, given that MCF10AT1 cells already express more mGluR1 than MCF10A. The way these genes interact and cooperate have not been investigated, and this provides an avenue for further research. Another analysis shows that mGluR1 is a mediator of angiogenesis and since the angiogenic process is highly dependent on VEGF, and PKC is a downstream mediator of VEGF activity, it is possible that PKC acts as a coincidence detector, whereby both VEGF and mGluR1 activity are required for its full activation [32]. 
While these suggestions are useful in understanding the changes that occur in the ESR signaling pathway during breast cancer, these mechanisms need further analysis to be accurate and reliable. Especially considering the small amount of cancer cell lines used for these specific reports.

\subsection{Crosstalk Effecting Src Inhibition}

Proliferation, motility, invasion are just a few of the functions the Src family contributes to through its interaction with mediators such as integrins and GPCRs. It is then logical to infer from these functions that Src may participate in cancer cell formation. Src kinase activation is common in various types of cancers although activating mutations and genomic amplifications are very rare [33]. In cancer, the overexpression of Src activation could be caused by the mutation of upstream proteins. These proteins are typically phosphatases or kinases as they control the phosphorylation of Src and consequently its activity. Src consists of two well defined protein-protein interaction sequences named Src homology domain 2 and 3 (SH2 and SH3) [34].

Current literature has linked and associated Src expression with the progression of breast cancer. One such report suggests that Src expression is most critical for TNBC as it was most sensitive to an inhibitor of Src, while ER+ breast cancer was not [35]. The study shows that by the inhibition of Src the levels of MAPK phosphorylation and/or Akt phosphorylation were reduced. It must be noted that because the definition of TNBC is not always precise, other factors should be accounted for to determine the effectiveness of Src targeted treatments for patients. This is one of the factors that causes Src inhibitors to not always be an effective treatment on its own. One report suggests that by combining the inhibitors of focal adhesion kinases and Srcs can reduce invasion, migration and mammosphere formation more efficiently than individual inhibitions [36].

The study suggests that Src inhibition reduced the expression of MMP9, which confirms other reports suggesting that MMP9 promotes tumor formation and progression. While it would be easy to assume that Src has one role and function in tumor formation, it has been determined that Src has multiple functions leading to the malignant phenotype of breast cancer. This is illustrated in HER2+ tumors, where it was observed that targeting Src signaling significantly sensitized resistant tumors to anti-HER2 therapies [37] [38]. Similarly, the observed detachment of the antiestrogen resistant cells after dasatinib treatment, a kinase inhibitor, may be the result of Src-mediated signaling to the focal adhesion kinase [39]. This explains why inhibitors that target Src need to be in conjunction with other inhibitors such as to focal adhesion kinase proteins. As mentioned previously, Src is a protein that cooperates with numerous proteins in breast cancer to promote tumor progression. This conclusion concurs with the implication that there is a functional crosstalk between EGFR and Src in the onset of lapatinib, an inhibitor of EGFR and HER 2, resistance [40]. Although much research has been done on investigating Src and the effects of its inhibi- 
tors, there are some aspects of Src that are still unknown. It would be beneficial to the community to continue investigating the associations Src has with other genes/proteins.

\subsection{GNAS More Influential than Other G $\alpha$ Proteins}

Heterotrimeric guanine nucleotide-binding proteins (G proteins) are molec-ular switches that control signal transduction, and their dysregulation can promote oncogenesis [41]. A G protein consists of $\alpha, \beta$, and $\gamma$ subunits present on the inner surface of the plasma membrane [42]. $G$ proteins become activated by binding to an appropriate GPCR, and facilitate the activation of numerous proteins including but not limited to small GTPases and second messengers. This results from the $\mathrm{G} \alpha$ subunit converting guanosine diphosphate to guanosine triphosphate, consequently the $\mathrm{G} \alpha$ subunit is critical to analyze and assess in cancer. However, the signaling system from the $\mathrm{G} \alpha$ subunit becomes complex since GPCRs can bind to more than one $G$ protein and lead to different pathways and

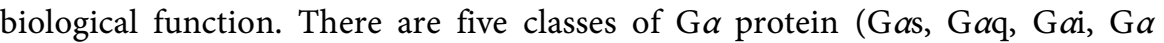
$12 / 13$, and the newly discovered Gav) and the GTP-bound con formations of each class interact with different canonical downstream effectors [43].

There is little information on the mechanisms of $\mathrm{G} \alpha$ during breast cancer, $\mathrm{G} \alpha$ subunits have been observed. Even though the $\mathrm{G} \alpha$ subunits are not well studied, there have been multiple reports suggesting that GNAS, a Ga subunit, is frequently expressed in breast cancer and functions in tumor progression. One report determines that GNAS was amplified in 20\% (10 of 50) of HER $2+$ breast cancers and 13\% (7 of 53) of HR+ breast cancers [44]. Another report suggests GNAS showed a high-level of amplification in the breast metastatic brain tumors that map to the stem cell pluripotency pathway [45]. A study evaluates the silencing of the GNAS locus and observes reduced growth of 20q amplified breast cancer cell lines [46]. The study identifies an extra-long $\mathrm{G} a$ s splice variant, in cell lines with 20q amplification, which can induce higher levels of cAMP than Gas. Research should also aim to explore other $\mathrm{G} \alpha$ subunits, since some other $\mathrm{G} \alpha$ subunits have been associated with cancer progression. For instance some TNBC over overexpress $\mathrm{G} \alpha 12$ and $\mathrm{G} \alpha 13$ and may cause cytoskeletal changes important for cell migration and metastatic spread [47].

\subsection{Metastasis through the Adapter Protein Grb2}

Growth factor receptor-bound protein 2 (Grb2) is an adaptor protein with no intrinsic enzymatic activity which is expressed in all eukaryotic cells [48]). The adaptor protein can exist as a monomer or a dimer, however its cellular properties and functions differ. When the protein is a heterotetramer there are at least two activation loop tyrosine residues (Y653 and Y654) of FGFR2 that are phosphorylated, but no downstream mitogen-activated protein (MAP) kinase signaling is observed [49]. The protein contains three domains; the center one is Src-homology 2 (SH2) and the other two are Srchomology 3 (SH3). The highly 
preserved SH2 domain is one of the most prevalent protein-binding modules for protein-protein interaction which mediate the formation of multiprotein complexes during signaling [50]. Grb2 is able to bind to numerous cellular phosphoand nonphosphoproteins through its $\mathrm{SH} 2$ and $\mathrm{SH} 3$ domains, respectively [51]. Since Grb2 has a wide range of proteins that it can bind to, Grb2 has been linked to a host of other cellular pathways including the actin cytoskeleton and endocytosis [52].

While Grb2 has been linked to breast cancer, it is not a necessary for tumor initiation and progression. While it may not be as critical as other proteins, research on Grb2 can still benefit the treatment of breast cancer. One report suggests that in estrogen-responsive breast cancer the Grb2/Ras/MAP kinase pathway is unlikely to transduce the integrin-dependent cell survival signal and is subsequently not likely to be effective in treatment unless combined with inhibition of IGF signal transduction [53]. Yet not all research is in agreement over Grb2s importance. For instance the analysis of gene expression data available from Oncomine datasets show that Grb2 is significantly overexpressed in breast cancer tissue compared to normal breast tissue, and patients who have low expression of Grb2 have a higher overall survival rate compared with those who have high expression of Grb2 [54]. The same study concludes that miR-411-5p inhibits breast cancer growth and metastasis mainly by targeting Grb2, emphasizing the importance of Grb2 in breast cancer.

\subsection{Complex Crosstalk of Akt}

The predominantly ubiquitous serine-threonine kinase Akt belongs to the protein kinase family AGC and exists either as the Akt1, Akt2, or Akt3 isoforms. All Akts require PIP3 to become activated. The three isoforms share over $80 \%$ homology and are characterized by three conserved functional domains: an amino-terminal pleckstrin homology domain that regulates intracellular trafficking of the protein, a central catalytic domain, and a carboxy terminal regulatory domain [55]. Each Akt isoform is unique and participates in different cellular processes and pathways by phosphorylating numerous proteins. Akt1 and Akt2 are widely expressed and especially high levels of Akt2 are present in the heart, skeletal muscle, adipose tissue, and testes [56]. Akt3 plays a role in postnatal development of the brain under normal physiological conditions [57]. Although the isoforms are unique in their function, all Akts are integral components for cell fate and participate in a variety of biological processes. The versatile serine is fundamental in many signaling pathways and increased activity of Akt is linked to multiple human diseases [58].

Most cancers are associated with amplification of Akt and breast cancer is no exception. The inhibition of Akt suppressed growth of MCF-7 xenografts in a patient-derived breast cancer resistant to tamoxifen and fulvestrant [59]. The same study proposes that the upregulation of IGF-IR/InsR and their ligands compensates for Akt inhibition in breast cancer cells with acquired resistance to 
estrogen deprivation. This implies that Akt inhibitors may have limited clinical activity in endocrine-resistant breast cancers when used as single agents. This has been shown in preclinical trials where Akt has activated the ER pathway independent of estrogen availability and the combination of mTOR inhibitors with endocrine therapy has overcome endocrine therapy resistance [60]. While Akt inhibitors are effective, they are more effective in conjunction with other inhibitors suggesting that there are feed-back mechanisms and overlapping functional mutations. This demonstrates the importance of building a model of the signaling crosstalk and pathways in order to predict outcomes and design appropriate treatments. Additionally, one study suggests that the decreased levels of Akt lead to decreased Bcl-2 expression, thereby swinging the balance of the cell toward apoptosis [61]. This only observes one protein expression change from Akt and there could be multiple changes in amplification by expression dysregulations of Akt. Isoforms of Akts may be more critical depending on the subset of breast cancer. As emphasized in one report stating that Akt3 is more prevalent in TNBC and amplification/overexpression of Akt is negatively associated with recurrence-free survival [62]. It would be beneficial to undergo a gene expression data analysis to determine the presence and expression of Akt in different breast cancer subsets.

\subsection{Ras Amplifications Rare but Significant}

Ras is arguably one of the most analyzed and researched genes in oncology. Indeed, since 2011, at a rate of 200 - 300 articles published per month, there have been more than 40,000 scientific articles published on the oncogene Ras [63]. Ras is a family of small GTPase proteins that contain three members which are found throughout the human body, HRAS, NRAS, and KRAS. However, KRAS has 2 isoforms KRAS4A and KRAS4B. Virtually ubiquitous in humans, Ras is activated by its phosphate binding pocket-P loop binding to GTP which occurs in response to a plethora of stimuli. When activated, the small monomeric protein acts as a hydrolase enzyme in the cytoplasm mediating cellular processes. Ras proteins play an important role in mammary signaling pathways, including the MAPK, PI3K and JAK-STAT pathways which control cellular functions, including cell proliferation, differentiation, migration and apoptosis [64]. Ras mutations and amplifications have been associated with multiple cancers and pathologies.

Each isoform of Ras has been linked to breast cancer. In general, mutations in Ras genes are very rare in human breast cancers [65], but the Ras signaling pathway is hyper activated in roughly half of these tumors [66]. KRAS, is particularly rare and its importance in breast cancer is hard to assess. Moreover, some studies report not detecting the presence of KRAS at all in TNBC (100 patients total) [67] [68]. However other studies reported KRAS mutation rates as high as $10 \%$ and propose that KRAS mutation may be predictive of grade 3 tumors [69]. This concurs with another report that suggests that TNBC tumors harboring the KRAS variant might be an aggressive subgroup of this breast cancer, as KRAS is 
an important upstream mediator of the MAPK pathway, and its overexpression can lead to increased activation of the Raf/MEK/MAPK pathway [70]. This suggests that KRAS is ultimately a rare mutation to observe but could be predicative of an aggressive tumor. It has been proposed that the concern with tumors possessing KRAS mutations is that activating mutations in the KRAS gene impair the ability of the KRAS protein to switch between active and inactive states, leading to cell transformation and increased resistance to chemotherapy and biological therapies targeting epidermal growth factor receptors [71].

Even though KRAS is the most frequently studied in regards to breast cancer, other Ras proteins have been researched and linked to tumor initiation, growth, and invasion. The different subsets of breast cancer seem to overexpress different isoforms, NRAS being more frequent in basal like breast cancer and HRAS more frequent in luminal breast cancer cells [72]. The same study proposes that NRAS in particular promotes tumor formation by activating cytoplasmic JAK2, leading to IL-8 induction and sequentially stimulating cancer cells and possibly stromal fibroblasts, thus creating a proinvasive microenvironment. NRASs role in later tumor stages has yet to be established and whether its involvement in the early stages occurs in response to growth factors and/or cytokines. It is speculated that HRAS and NRAS differentially regulate the invasive and migratory properties of breast epithelial cells [73]. Taken together, these reports imply that a further study needs to analyze a larger patient sample to determine a more reliable analysis of the frequency of these gene variants in breast cancer (Figure 2).

\subsection{Consensus in Literature but Few Studies on SOS}

In humans there are two Son of Sevenless (SOS) homologues, hSOS1 and hSOS2. SOS1 is a guanine nucleotide exchange factor that promotes RAS and RAC activation downstream of EGFR and other growth factor receptors [74]. The guanine nucleotide exchange factor promotes Ras by catalyzing the conversion of the inactive GDP-bound form of Ras to its active GTP-bound form [75]. SOS proteins comprise of multiple domains that are functionally unique. The $\mathrm{REM}$ and the $\mathrm{CDC} 25 \mathrm{H}$ domains map next to each other between the helical linker (HL) and the proline-rich motif, while the $\mathrm{N}$-terminal region contains the histone-like domain, the Dbl homology domain, the pleckstrin domain, and the HL which is the most frequently mutated [76]. The REM domain is where SOS binds to Ras-GTP, although this is only possible when SOS is localized to the cell membrane.

Surprisingly, there has been very little research on SOS1s relation to breast cancer. This is particularly surprising because of its involvement with Ras, which is observed in multiple types of cancers. Regardless, SOS1 has been considered in breast cancer, hematological malignancies, and skin cancer most likely through its participation in the reorganization of the actin cytoskeleton (ruffling 


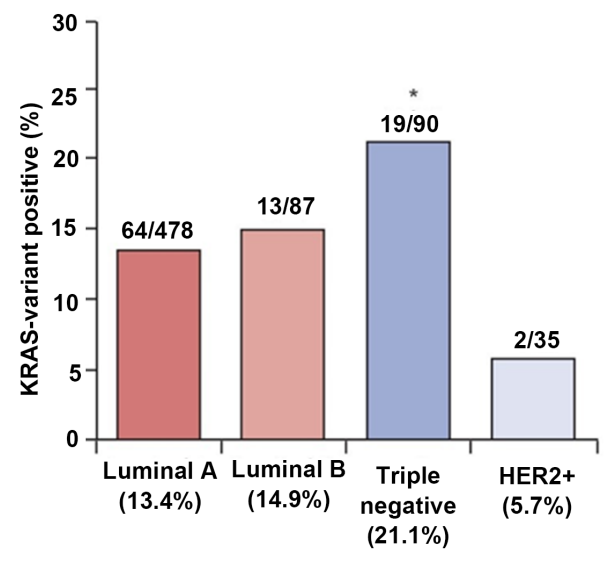

(a)

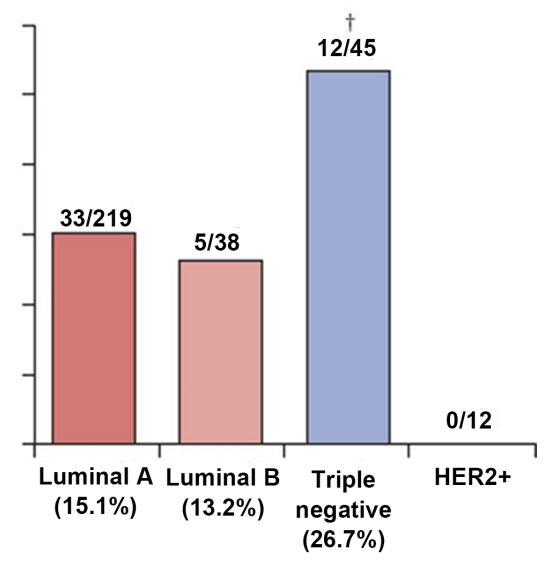

(b)

Figure 2. Distribution of the KRAS variant in breast-cancer subtypes in all women (a) and premenopausal ( $\leq 51$ years) women (b) non premenopausal women 70 .

membranes, lamellipodia protrusions), cell invasion and migration [77]. Some speculate that higher expression of SOS1 may contribute to the more aggressive phenotype and poor prognosis in African American women [78]. However, since African women are up to three times more likely to have TNBC [79], this correlation with SOS1 may be due to the aggressiveness of TNBC. DAG Involved in Cell Growth but Not Well Studied in Breast Cancer Diaclglycerol (DAG) is a lipid which functions as a second messenger and is involved in multiple signal transduction pathways. Significantly, it activates both the classical and novel PKC. Specifically, both classical (cPKC) and novel PKC (nPKC) respond to DAG generation, although atypical PKC (aPKC) activation is DAG-independent [80]. aPKC cannot bind to DAG due to the absence of DAG-binding motifs. Regardless, it can be concluded that DAG is a critical molecule in cellular biology and may have significant effects on cell growth. DAG is a product of the hydrolysis of the phosphatidylinositol-4,5-bisphosphate (PIP2) by the enzyme phospholipase C (PLC) that also produces inositol 1,4,5-triphosphate (IP3) implicated in $\mathrm{Ca}^{2+}$ release from the endoplasmic reticulum [81].

Despite DAGs involvement in cell growth there has been very little current research on DAGs involvement in breast cancer. However, it has been determined that inhibition of DAG synthesis with Triacsin C completely reversed stearate-induced caspase 3 activity in two breast cancer cell lines [82]. Caspase 3 is known for its apoptotic functions, showing that DAG somehow is involved in cell survival during breast cancer.

\subsection{CAMs Significant Interactions with Multiple Proteins}

Calmodulin (CAM) is a small $\sim 16 \mathrm{kDa}$ protein that is ubiquitously expressed throughout the human body and can bind to the secondary messenger $\mathrm{Ca}^{2+}$, thereby regulating multiple cellular processes via changing the concentration of $\mathrm{Ca}^{2+}$ within the cell. These processes can include apoptosis, cell motility, protein 
folding, metabolic homeostasis and numerous others. The highly conserved CAM is composed of two globular domains and one peptide chain with four $\mathrm{Ca}^{2+}$ binding sites [83]. While its regulation of free $\mathrm{Ca}^{2+}$ is a major factor in leading to all of these cellular processes, another major factor is its ability to bind to a multitude of other proteins. Consequently, CAM is a difficult protein to target without severe consequences in drug therapy. Regardless, during cell cycle progression, the concentration of CAM progressively increases, reaches high levels at the G1/S transition, and remains high during the ensuing progression of the cell cycle [84]. CAM regulates apoptotic processes both positively and negatively mediating elevated intracellular $\mathrm{Ca}^{2+}$ mediating elevated intracellular $\mathrm{Ca}^{2+}$, which can have both growth promoting and cell death-inducing consequences [85].

While there is literature assessing CAMs involvement in cancer, there is less research on its involvement in breast cancer. It has been shown that CAM can bind directly to death receptor 5 in a calcium-dependent manner in both a ER+ and a TNBC cell line [86]. By binding to the death 5 receptor this could prevent the receptor from mediating apoptosis in these cancer cells. Another study shows that there is a strong relation between the k63-linked ubiquitination protein and the CAM-like protein 5 (CALML5) and the carcinogenesis of the breast in young women [87]. Lastly, inhibition of CAM function or disruption of CAM-HER2 interaction reduced HER2 phosphorylation and HER2-stimulated cell growth [88]. Regardless of the protein bound to CAM, it appears that CAM serves a critical role in preventing programmed cell death in breast cancer cells.

\subsection{Not all Rafs Created Equal in Breast Cancer}

Currently, there are 3 known isoforms of Raf, ARaf, Braf, and Craf, all of whom are serine/threonine kinases activated by recruiting to Ras and dimerizing. There is high homology and similar domain organization between the isoforms [89]. While all of the Rafs share the same substrate, MEK1/2 kinase, their activity varies between them. The general Raf structure can be split into a regulatory $\mathrm{N}$-terminal region, containing the Ras binding site, which is critical for activation as well as inhibitory phosphorylation sites, and a catalytic C-terminal region, which includes phosphorylation sites necessary for the kinase activation [90]. Since these regions are conserved and found in all isoforms, it is not surprising that all members of Ras can bind to all isoforms of Raf. Most research has been conducted on CRaf, however BRaf has recently caught the attention of some studies, while there have been very limited studies regarding ARaf [91].

The CRaf isoform has been observed and associated with breast cancer before any other isoform. Although, some research has recently been aimed at BRaf in breast cancer, its functions and activity in breast cancer is not fully understood. Research on BRaf may be difficult since, BRaf is only mutated in about $3 \%$ of breast cancer patients [92]. CRaf has been shown that its knockdown inhibited breast cancer cell survival and promoted them to apoptosis cells [93]. CRaf has not only been shown to be associated with breast cancer, but in the most aggres- 
sive breast cancer subset, TNBC. It was found that CRaf was frequently upregulated in TNBC in comparison to 3 other main breast tumor subgroups, further highlighting the heterogeneity of the TNBC subgroup and the difficulty of finding a specific target [94].

Some mechanisms have been speculated for CRafs effect on proliferation in breast cancer. For instance, it is suggested that CRaf amplification induced by RAD51 downregulation may be a "necessary but not sufficient" effect of RAD51 on breast tumor initiating cells, and these compensatory mechanisms might help sustain stem/progenitor cell survival under DNA damage and genomic instability, which could further lead to deregulated signaling changes enabling breast tumor initiating cells to outgrow and expand [95]. However, other more general to Raf protein mechanisms have been proposed. Using a robust 3D culture model that approximates formation of mammary acini, it was shown that hyperactive Raf/MEK/extracellular signal-regulated kinases (ERK/MAPK) pathway leads to increased MMP9, which destroys tissue polarity and growth control [96]. In terms of migration, it is suspected that EGF and SDF- $1 \alpha$ mediated migration of M13MDA435-1 hybrid cells was most likely attributed to an active Raf-Akt crosstalk in these cells [97]. While these general mechanisms are useful for constructing a mutated ESR pathway of breast cancer, ARaf has not been taken into account and therefore should be examined to determine their role in the pathway.

\subsection{MEK Synergy with EGFR}

Mitogen activated protein kinase kinase (MEK) is a family of 7 proteins that are involved in the ESR pathway, often regulating apoptotic behavior. While the MEKs are similar to one another, they are involved in different protein activations. MEKs serve vital roles among species as the regulated phosphosites are highly conserved in all species of human, mouse, Arbidopsis, Drosphila C. elegans, and even yeast [98]. All Meks comprise of an N-terminal domain and a C-terminal domain, as well as a catalytic domain. MEK1 and MEK2 are known to participate in the Ras/Raf/MEK/ERK signal, Mek3 and Mek6 phosphorylate residues in the $\mathrm{p} 38$ MAPK, Mek4 and Mek7 activate JNK protein kinases, while Mek5 interacts with MEKK2, MEKK3 or ERK5 [99]. Mek1 and Mek2 are the most studied out of the Mek family. Mek1/2 are serine/threonine kinases that have dual-specificity and when activated can catalyze the phosphorylation of ERK1/2 [100].

Currently, it is known that MEK is associated with tumor growth and formation, despite disappointing clinical trials. This most likely occurs either from cytotoxicity or from overlapping functions of other proteins. Specifically, some TNBC cell lines have shown resistance to MEK inhibitors in pre-clinical studies and early clinical trials have not shown activity of these agents in different tumor types, thus underlining the need to better understand the mechanisms regulating resistance to these drugs [101]. By combining inhibitors there has been some success in therapy. As emphasized by the simultaneous blockade of MEK and EGFR producing a synergistic growth inhibitory effect in all the TNBC cell lines 
tested [102]. However, this was a relatively small study and it would be beneficial to further study the effects of EGFR and MEK inhibitors not only in TNBC but in other cancer cell lines to evaluate any differences and effects. One study observers that inhibition of just MEK was capable of completely abolishing anchorage-independent growth, cell invasion, and cell migration in TNBC [103].

\subsection{Tumorigenesis and Invasion via FKBP52}

FK506 binding proteins (FKBPs) function as protein folding chaperones for a multitude of proteins. Specifically, FKBP51 and FKBP52 are Hsp90 co-chaperones that modify steroid hormone receptor (SHR) activity [104]. However, it is important to note that FKBP51 and FKBP52 only interact and regulate some SHRs but not all. Structurally, FKBP52 consists of a C-terminal Hsp90-binding TPR domain, an N-terminal FK1 domain that contains a functional peptidyl/prolyl isomerase (PPIase) active site to which the immunosuppressive ligand FK506 binds, and a middle FK2 domain that is similar to FK1 but lacks PPIase activity [105]. Altogether these regions make up a $\sim 51 \mathrm{kDa}$ protein which is a family member of the immunophilins, functioning as endogenous cytosolic peptidyl-prolyl isomerases [106]. Consequently, it is expected that FKBPs are involved in the immune system and immune pathologies; however, it may not be so apparent that they are also involved in cancer.

It is interesting to note, that while these proteins have been associated with numerous cancers, whether it promotes or inhibits tumors is not predictable. For example, FKBP5 is found to be down regulated in pancreatic tumor tissue, while it is overexpressed in melanoma [107]. Most research regarding breast cancer however has shown that FKBPs are overexpressed and promote tumor development. One such study explains that because depletion of FKBP5 led to decreased CDK4 protein levels and CDK4 kinase activity in breast cancer, considering that CDK4 is hyperactivated in tumorigenesis, it indicates that FKBP5 promotes oncogenesis in part by stabilizing CDK4 [108]. Additionally, the increased expression of FKBP5 in breast cancer cell lines has also been associated with invasion in breast cancer cells as well as tumorigenesis [109]. Other FKBPs have also been associated to drugresistant cell lines which may explain the invasiveness and responsiveness of these cell lines. Specifically, it was shown that FKBP4 was upregulated in the drug-resistant cell lines SK-BR-3 (ER negative) and MCF7 $(\mathrm{ER}+)$ in comparison to other cell lines, which indicates that FKBP4 expression correlates to drug responsiveness [110]. However, these studies do not look into other FKBP proteins, and it would thus be useful to examine other FKBPs to have a comprehensive understanding of their effects in breast cancer.

\subsection{The Vasodilator NO Participates in Angiogenesis}

As a ubiquitous gaseous molecule, it is expected that nitric oxide (NO) reacts rapidly when produced by nitric oxide synthase (NOS). Although NOS catalyzes the reaction, production of NO is also facilitated by NADH and oxygen. The actions of NO are mainly mediated through cGMP-dependent manner as well as 
cGMP-independent manner, typically through NO targeting the heme component of soluble guanylyl cyclase, which further undergoes coupling with c-GMP-dependent protein kinase G and phosphodiesterases as well as cyclic nucleotide gated channels [111]. When produced the, relatively small free radical, water soluble, $\mathrm{NO}$ is capable of diffusing out and stimulating a diverse range of cellular events, such as vasodilation and inflammation, however, $\mathrm{NO}$ is unstable and breaks down easily. While NO function is critical for healthy cells, its dysregulating has been implicated as a causal or contributing to pathophysiological conditions including cancer [112].

One of the key contributors of NOs involvement in cancer, including breast cancer, is its participation in vasodilation, as this process facilitates angiogenesis in tumors. Although this hasn't been replicated in breast cancer is has been shown that NO induces angiogenesis by modulating the level of the angiogenesis inhibitor thrombospondin 2 via EGFR signaling pathway, VEGF, and p53 [113]. It would be therefore interesting to examine the association of these proteins during breast cancer development. Furthermore, it is proposed that NO can modulate tumor aggression in breast carcinoma through the inhibition of enzymes linked to DNA repair machinery [114] [115]. However, the latter source suggests that while there were increased levels of $\mathrm{NO}$ in breast cancer patients, there was no correlation between metastatic and non-metastatic patients, indicating that $\mathrm{NO}$ is not involved in such events.

\subsection{CREBs Involvement with MMPs Promotes Metastasis}

As a ubiquitous transcription factor, cAMP response element binding protein (CREB) binds to DNA and subsequently regulates diverse biological processes and pathways. In fact, CREB targets genes that are involved in cell metabolism, survival, proliferation, differentiation, cell cycle, DNA repair, immortalization of cells, inflammation, immune modulation and more [116]. Although there are many downstream molecular targets of CREB some of these include brain-derived neurotrophic factor, B-cell lymphoma 2 protein, c-Fos transcription factor, and corticotropin release factor [117]. Depending on the target gene, CREB can act as a repressor or activator for transcription. Activation occurs from numerous extracellular signals including but not limited to hormones, growth and neurotrophic factors, neurotransmitters, and membrane depolarization [118]. In order to be activated CREB must be phosphorylated at the Ser-133 residue which then enables it to bind to the cAMP-responsive element sequence "TGACGTCA" [119]. The binding of DNA is facilitated by CREB's leucine zipper domain by dimerizing two DNA regions. Enzymes that catalyze the phosphorylation of CREB include protein kinase A (PKA), Akt, CAM-dependent protein kinase, and MEK/ERK [120].

While CREB is better known for its role in Alzheimer's disease and cardiovascular diseases, it is less known for its involvement in cancer. However, there have been studies conducted towards determining its functions and associations to cancers, including breast cancer. Foremost, CREB-2 has been shown to play 
critical roles in stress-induced angiogenesis through VEGF signaling, which is vital for tumor growth and metastasis [121]. However, this study is not breast cancer specific and would consequently need to be tested in breast cancer cell lines. Although recent studies have not focused on angiogenesis and CREB, studies have largely focused on CREBs association with metastasis in breast cancer. One study shows that CREB signaling in breast cancer regulated the gene expression of parathyroid hormone-related peptide, MMP2 and MMP9, and osteoprotegerins, which are closely involved in cancer metastasis and bone destruction [122]. This is supported by another study which found that CREB2 was not only over expressed in breast tumors but was associated with lymph node metastasis in infiltrating breast carcinoma [123].

One way CREB may be involved in metastasis by its ability to mediate cell survival signaling [124]. Essentially, this would enable cells to be anchorageindependent unlike healthy cells which undergo apoptosis when unanchored. Cell survival signaling would benefit cell cycle progression, despite DNA damage causing mutations. These effects are demonstrated by the downregulation of CREB in HER-2 transformed cells which causes reduced cell proliferation by cell-cycle arrest, cell migration, MMP expression, but with increased fibronectin adherence [125]. Overall, this research provides a glimpse into the functions of CREB, however other variations of CREB remain to be analyzed. Therefore, future research should observe other CREB variations in order to see if there are further correlations between CREB and breast cancer. Regardless, these studies have shown that CREB is specifically critical for breast cancer metastasis and cell survival, which should be considered during prognosis of patients.

\section{Varied Correlations to Breast Cancer}

This section includes genes where there are either inconsistencies in the literature, or whether there is consensus on a gene being both a tumor suppressor and promoter depending on factors such as breast cancer subset and chemical microenvironment.

\subsection{Possible Resolution of E2 Discrepancies}

$17 \beta$-Estradiol (E2) is an integral component in the regulation of the female reproductive cycles. E2 is biosynthesized from progesterone (arrived at in two steps from cholesterol, via intermediate pregnenolone) [126] and is a ligand to Estrogen Receptors (ERs). Although the steroid is found in males, its roles and effects in males are perplexing and not fully established by the medical community. In females however, E2 functions as a growth hormone for the reproductive system and tissues such as bone tissues and brain tissues. In our case, the most significant being its involvement in the development of breasts. Due to this involvement, it is not surprising that E2 has already been associated to breast cancer. In fact, epidemiological evidence indicates that most breast cancer risk factors are associated with prolonged exposure of the mammary gland to high levels of E2 [127]. 
In one report, it is shown that E2 is able to induce complete neoplastic transformation of human breast epithelial cells, as proven by the formation of tumors in severe combined immunodeficient mice [128]. Though these results facilitate our understanding of the formation of breast cancer, it must be noted that this report basis its analysis off severe combined immunodeficient mice and consequently is less representative of results that may happen in humans. Moreover, it is now suggested, that while E2 has a role in tumor formation, the important issue for the decision of breast cancer cells to survive or die in response to estradiol depends entirely on the cell populations present in an estrogenized environment or following estrogen deprivation [129]. Based on the laboratory data they assessed, the decision is survival or death, respectively. E2 may also be involved in breast cancer cell movement and invasion by the extra-nuclear activation of the actin-binding protein ezrin [130]. Furthermore, it has been proposed that E2 induces proliferation via SDF-1/CXCR4-mediated activation of EGFR that in turn activates both Akt and ERK1/2 cascade [131]. The study speculates that besides a role in cell migration, Akt activation by E2 and SDF-1 is also involved in breast cancer cell proliferation. Although some literature seems to be in accordance with this research, it would be beneficial to further explore the interrelatedness of these genes. While this acts as a platform to begin constructing a model of the mechanisms and pathways of E2 in breast cancer, it is not yet a completely reliable and accurate representation of E2s role in tumor progression.

\subsection{Each Variation of MMP Has Unique Function}

The endopeptidases matrix metalloproteinase (MMPs) function was originally restricted to tissue remodeling and maintenance, as they are capable of degrading extracellular matrix (ECM) proteins. However, recent studies have revealed that they participate in innate and adaptive immunity, inflammation, angiogenesis, bone remodeling, and neurite growth [132]. MMPs are capable of many functions because unlike most proteins they are not specific to a particular ligand, enabling them to bind to a multitude of ligands. They are multi-domain proteins and their activities are regulated by tissue inhibitors of metalloproteinases [133]. So far, there are more than 24 gene variants of MMPs that have been observed in humans. With so many known variants it is unsurprising that MMPs represent the most abundant ECM regulator within the tissue microenvironment [134]. All MMP variants except MMP-23 comprise a pro-domain upstream of the catalytic domain, and activation proceeds through its removal [135].

While MMPs are necessary in humans to prevent tissue disruption, numerous MMPs have been associated with breast cancer, especially during metastasis and invasion. One report observed that MMP-1, -9, -11, -15, -25, and -25 were upregulated in breast cancer tissues compared to normal breast tissue, whereas MMP10 and MMP19 were downregulated [136]. Although it is agreed upon in the literature that MMPs are somehow involved in breast cancer, the particular 
MMPs vary from report to report. Even though this report takes into account 39 samples from breast cancer and 16 from healthy patients, the results differ from other reliable sources. For instance, another report suggests that MMP2 is overexpressed and is more active in metastatic breast cancer [137]. It would seem that particular MMPs are involved in specific stages of breast cancer and consequently further research needs to be done regarding MMPs and their roles and functions throughout tumor progression.

Since there are varied results for which MMPs are associated with breast cancer, it is understandable that the exact mechanistic nature of MMPs during breast cancer is varied as well. However, with that being said, the general outline is that during malignant progression, MMP activity becomes deregulated, which contributes toward the disruption of normal tissue ECM, and also the abnormal regulation of several signaling pathways [138]. It is believed that altogether MMPs play a critical role in breast cancer initiation, growth, angiogenesis, invasion, and metastasis [139]. Some MMPs have been more thoroughly investigated than others, for example MMP1 has been observed to regulate the levels of transforming growth factor $\alpha$ which in turn affects the activation of EGFR in breast cancer cells [140]. EGFR is relevant to breast cancer as its ligand has been linked to promoting heparanase function and topoisomerase I localization in brain metastasizing breast cancer cells [141]. This information can then facilitate our medical community in development of drugs and treatment, however, to improve it is vital that we pinpoint which MMPs the most critical in breast cancer and how they function during tumor development.

\subsection{GABA and OPRM1 Located in the Brain Yet Influence Breast Cancer}

Even though gamma-aminobutyric acid (GABA) is the primary inhibitory neurotransmitter in the mature human brain, it is known to be involved in a large spectrum of functions throughout the body. Although the $\mu 1$-opioid receptor (OPRM1) is not a neurotransmitter itself, it is a receptor for neurotransmitters and is predominately located in the brain with GABA. GABA can act as a trophic factor during nervous system development to influence cellular events including proliferation, migration, differentiation, synapse maturation, and cell death [142]. In fact, GABA has been shown to influence the development of a variety of tissues and organs, including but not limited to the pancreas [143], liver [144], and even stem cells [145]. When bearing in mind that GABA is involved and contributes to cell proliferation throughout the body, it becomes apparent to why GABA would be evident in multiple types of cancers, including breast cancer. On the other hand, it is not so apparent how OPRM1 is involved in breast cancer.

Even though it would seem logical to presume that GABA somehow promotes tumor formation, little research has been done on its presence in breast cancer. GABA's effect and role in breast cancer could have a serious impact on the medical community considering that some research has indicated that GABA can act 
as a tumor promoter or as a tumor repressor depending on the particular cancer. For instance, in liver cancer GABA suppressed the cancer cells from migration and invasion [146], while in pancreatic cancer it has been speculated that GABA promotes tumor progression [147]. It is suspected that GABA can significant promote the invasive ability of prostate and renal cancer cells through the production of MMPs [148]. Due to the varied response of GABA during cancer, it would be especially relevant to explore its function in breast cancer. Whereas GABA has been studied in some cancers, due to OPRM1s association with morphine/opium, the receptor is less established in the study of cancer let alone breast cancer. However, recent studies have linked OPRM1 and gene variants to breast cancer. For instance, breast cancer-specific mortality was significantly reduced in patients with a genetic variant (A118G) in the $\mu$-opioid receptor that reduces opioid response [149]. Even though the same study admits that one limitation of their study is that gene association studies cannot definitively show that particular outcomes are actually caused by a specific mutation/gene. Despite this limitation, other studies concur with these findings. Particularly, one study reports that carriers of the same polymorphism had more than three times increased breast cancer risk than both healthy female and the entire control group [150].

Although there is growing evidence for an effect of the family of OPRM1 in mediating tumor metastasis, the reason for this effect remains unclear [151]. One process of thought is that opioids appear to suppress a number of aspects of immune system function, and some of these effects have been shown to be mediated by OPRM1 activation [152]). Other data suggests that OPRM increases PTEN/p53 via PI 3 kinase Phosphatidylinositol-4,5-bisphosphate 3-kinase and protein kinase $\mathrm{B}$ (PI3K and Akt respectively) signaling pathway in some cell lines, including MCF7, T47D, and MDA-MB231 [153]. Since the information on OPRM1s involvement and function in breast cancer is so limited it would be efficacious to determine whether any other variants are involved in breast cancer. Moreover, a molecular dynamics study would offer insight on some of the associations and mechanisms of OPRM1 with other genes in the ESR pathway.

\subsection{Inhibitors of AC Cause Conflicting Effects}

Cyclic adenosine monophosphate (cAMP) is a secondary messenger molecule and is typically produced by the cleavage of adenosine triphosphate (ATP) catalyzed by adenylate cyclase (AC). AC is bound to the cell membrane and its activity is regulated by the concentrations of hormones and chemical signals. As a secondary messenger, cAMP is critical in multiple signal transduction cascades, and consequently $\mathrm{AC}$ is a vital molecule to analyze and investigate. In prostate cancer AC is observed to generate a rise in cAMP and subsequently proliferation from a cross-talk between cAMP signaling and androgen receptors via PKA activation [154].

However, there is currently less information on ACs involvement in breast cancer. Observations have lead to the conclusion that the chemopreventative 
agent, Resveratrol, stimulates AC in human breast cancer cells through cPLA2-dependant pathway [155]. Paradoxically, another report suggests that antiproliferative effects in cancer therapy occur via the inhibition of AC [156]. However, there is little recent data on AC and its appearance in breast cancer particularly, so it would be efficacious to know its presence and regulation patterns in breast cancer through gene expression data analysis methods such as, Hierarchical Clustering, Self-Organized Map, and Consensus Clustering.

\subsection{Localization of Estrogen Receptor Is Significant in Breast Cancer}

While membrane-bound Estrogen Receptors (mERs) are similar to nuclear ERs there are subtle differences in their functions and effects in the cellular environment. Non-genomic pathway regulates more genes than just genomic action of ER alone, such as proliferation, apoptosis, and survival [157]. However, it must be noted that most ERs are not restricted to the membrane or cytosol. For instance, ER $\alpha 36$ can be located in plasma membrane, nuclear, and cytosolic fractions. Although, it is more common to detect ER $a 36$ bound to the plasma membrane. It is known that mERs rapidly signal as GPCRs to generate calcium flux, stimulate cAMP and cGMP production, and trigger phosphoinositide 3-kinase (PI3K) and ERK pathway activation [158]. In fact, one mER exists as a G protein-coupled estrogen receptor (GPER). Although it was once referred to as the $G$ protein-coupled receptor 30. It was later changed as it was determined that GPER can bind to estradiol and consequently is now considered an ER. The seven transmembrane-domain protein mediates the effects of estrogens in a wide number of cell types to produce rapid non-genomic biological responses [159].

Even though all ERs have been associated with breast cancer, mERs should be explored separately since their mechanisms by which they function are unique. This is illustrated in one report which observes that when a xenograft model of MCF-7 human breast cancer cells were injected into nude mice, engagement of only mERs by an estrogenic compound failed to stimulate proliferation of the tumor [160]. The study later proposes that communication between extranuclear and nuclear ERs is likely to be important to promote the growth of human breast tumors. In contrast to this, one study reports that specifically membrane localization of ER $\alpha 36$ in TNBC provides a survival benefit of 16 months, while no correlation between intracellular ER $\alpha 36$ and prognosis [161]. Similarly GPER was found to inhibit growth of ER $\alpha+$ breast cancer, which may indicate better prognosis [162]. However, the same study finds that GPER can induce proliferation in another breast cancer cell line. While this information is significant as it could be applied to determine prognosis factors for patients, it is specific towards a subset of breast cancer, and should be further explored in other subsets.

Not only has there been research dedicated to the associations of mER with breast cancer but there have also been some suggested mechanisms for the interactions of mERs. One study depicts a novel cross-talk mechanism in which 
EGFR and ER $\alpha 36$ positively regulate each other in TNBC, however ER $\alpha 36$ may dynamically change its partners during estrogen signaling in regards to EGFR and Src/Shc [163]. A mechanism for GPER has also been speculated. Specifically, upregulation, stabilization, and nuclear translocation of p53 by activation of GPER is involved in G-1-induced growth arrest of ER-breast cancer cells [164] [165]. However, this speculation is only for one subset of breast cancer, and cannot be assumed for other subsets, especially because GPER has also been associated with promoting tumor development [166] [167] [168]. Although one mechanism for cell proliferation is proposed by Ignatov et al., which suggests that activation of GPER results in stimulated proliferation via EGFR transactivation. Since there are discrepancies in the literature, a study should aim to elucidate the cause for the tumor suppressor and promoter activity of the ERs.

\subsection{Model of Shc}

Src-homology collagen (Shc) proteins can be recruited to cell surface growth factor RTKs. The resulting complex relays and amplifies an exquisitely fine-tuned regulation of multiple downstream signaling events, which depending on cellular context, mediate specific biological response [169]. However, RTKs more typically recruit Grb2 than Shc, although others recruit both. Even so, Shc proteins interact with diverse signaling molecules in addition to Grb2, thereby engage in Grb2-independent pathways and biological functions [170] [171] [172] [173] [174]. Within the Shc family there are four members, two of them only detected in certain human tissues, one of them only found in mice, and lastly one of them, ShcA, is expressed ubiquitously in the human body. ShcA is the only family member that has been implicated in human breast cancer and has three isoforms: p46Shc, p52Shc, and p66Shc. However, Shc isoforms functions are complex and can seem contradictory, particularly in cancer. As shown in colorectal cancer cells where they induced migration of cancer cells [175], while in another was shown to suppress migration in lung cancer cells [176].

While typically Shc has been correlated to promoting metastasis and tumor progression in breast cancer, there are some studies which show otherwise. However, one report suggests that the association between high p66ShcA levels and good outcome is reflective of the fact that p66ShcA is enriched in luminal breast cancers which have a better prognosis than other subsets [177]. This suggests that p66Shc enhances signaling downstream of the Met RTK and that Mets activation is required for p66Shc to induce epithelia-mesenchymal transition in luminal breast cancer. While Shc is a member of the ESR pathway, it must be noted that there are other genes that aren't found in the normal ESR pathway that it can interact with. One study associates p66Shc with ARF1 and ARF6 (as illustrated in Figure 2) which then may lead to cell proliferation and tumor cell migration in breast cancer. Whether these genes should be incorporated within a new mechanistic model of the ESR pathway in breast cancer should be considered and reviewed in future studies. 


\section{7. cAMPs Involvement May Depend on Subset of Breast Cancer}

As a second messenger, cAMP is an integral component to multiple biological pathways, such as olfaction and synaptic transmission. The intracellular levels of cAMP are regulated by the balance between the activities of two enzymes: AC and cyclic nucleotide phosphodiesterase (PDE) [179]. However, both ACs and PDEs are regulated by multiple other proteins, such as GPCRs and CAM. AC and PDE have opposite catalytic activities, while PDE me diates the cleaving of cAMP, AC mediates the production of cAMP from ATP. The balance of cAMP signaling is essential to multiple cellular processes, including immune function, growth, differentiation, gene expression and metabolism [180]. Within the same cell elevated cAMP levels and subsequent PKA activity by different agonists can lead to different physiological responses due to the cellular distribution of the isoforms their particular biochemical properties [181]. The effects of cAMP are varied and consequently it is logical to expect that cAMPs activation in cancer can be varied. This is emphasized by one study which observes that the effect of cAMP differs between different types of lymphoid cell and concludes that the activation of the cAMP pathways may either induce or inhibit cell proliferation and apoptosis (Figure 3) [182].

Similarly, there have been contradictory results of cAMPs effect in breast cancer. While one report suggests that breast cancer cell migration is significantly inhibited by the activation of cAMP signaling, through either application of cell permeable cAMP analogs or by treatment with PDE inhibitors [183]. Another study claims that the positive cAMP/ $\mathrm{Ca}^{2+}$ loop is linked to increased invasion of breast cancer [184]. These reports are in direct contrast to one another, and consequently suggest that cAMPs function in breast cancer must alter depending on other cellular factors. One of these factors could be that the former report used multiple cell lines, including ER+ and ER-cell lines, while the latter only used one TNBC cell line. Therefore, it is critical that research focuses on determining what factors elicits the alternation of cAMPs influence on breast cancer cell migration.

\subsection{Alternative Methods Needed for PI3K Prognosis Analysis}

Phosphoinositide 3 kinases (PI3Ks) are an integral component in the integration of signals from a variety of stimuli including nutrients and oxygen, which results in numerous downstream responses. The lipid kinases become activated by the binding of a growth factor or ligand to its appropriate RTK. When activated the family can recruit effector proteins and thereby modifying their activity, conformation and localization; sometimes these events are mediated by binding protein domains [185]. While there are multiple classes of PI3Ks, class IA PI3Ks are heterodimers comprised of a regulatory subunit (referred to as p 85) and a catalytic subunit ( $p$ 110), and are typically deregulated in cancer [186]. The activation of PI3K has been commonly implicated in many cancers including breast cancer, through mutations that amplify the PI3K pathway. 


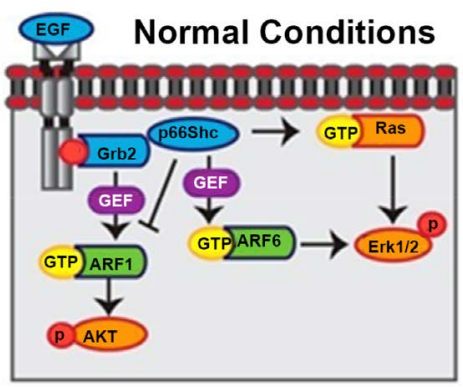

(a)

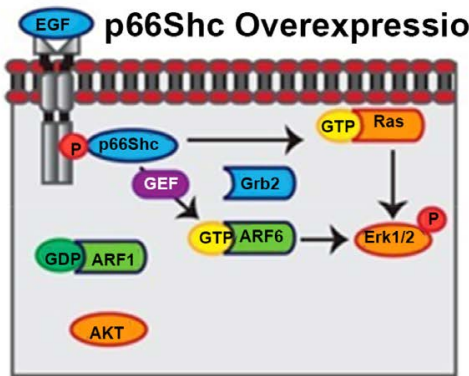

(c)

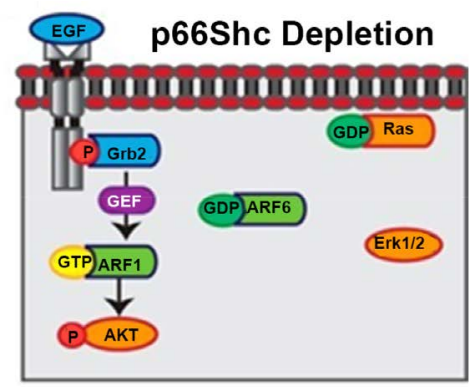

(b)

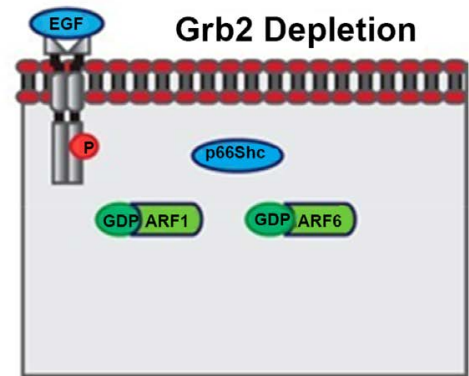

(d)

Figure 3. Model of ARF1 and ARF6 activation downstream of the EGFR in MDA MB-231 cells [178].

PIK3CA mutations are reported to be present in approximately $25 \%$ of breast cancer, making them one of the most common genetic aberrations in breast cancer, yet a report finds that PIK3CA mutations were not associated with a poor clinical outcome despite their known tumorigenic effects through activation of the PI3K pathway [187]. Furthermore, some studies suggest that PIK3CA is indicative of good long-term outcome and lower PI3K and TORC1 activation as assessed by gene expression profiling and immunohistochemistry in patients bearing ER+ tumors [188] [189] [190]. However, the correlations between PIK3CA mutations, good patient outcome, and low PI3K pathway activation (measured by gene expression profiling and immunohistochemistry) beg the need for alternative methods indicative of PI3K pathway activation to identify $\mathrm{ER}+$ tumors at risk of recurrence [191]. This is even more relevant considering that PIK3CA seems to be more prevalent in particular subsets of breast cancer. That is activating mutations in PIK3CA occur more frequently in luminal A, luminal B, and HER2+ breast cancers $(45 \%, 29 \%$, and 39\%, respectively) as compared to basal-like breast cancers (9\%) [192]. One of the major issues in the analysis of PI3K is the numerous amount of mutations that complicate functions and the pathway, additionally there is a lack of appropriate tumor specimens for analysis. To improve current research it would be useful to analyze all tumor samples publicly available as well as focusing on expanding the collection of tumor samples for public use. As emphasized by Juric et al who states that the conduct of large correlative studies with banking of sufficient tumor samples for mutation analysis is essential in order to identify biomarkers that will guide the management of a malignancy as heterogeneous and complex as breast cancer [193]. 


\subsection{Discrepancy of PKC in Breast Cancer Is Unresolved}

Protein kinase $\mathrm{C}(\mathrm{PKC})$ is a family of 10 phospholipid dependent serine-threonine kinases that are then categorized into three subclasses. One of which are the Novel PKC which comprises of PKC $\delta, s, \eta$, and $\theta$. The novel PKC subclass are categorized by their altered $\mathrm{C} 2$ region which is unable to bind to $\mathrm{Ca}^{2+}$ making them $\mathrm{Ca}^{2+}$ independent, and can be activated by DAG and phorbol esters [194]. However, it is important to note that although PKC isozymes are from the same family, they are structurally and functionally different from one another, which consequently makes modeling the signaling pathway complex. PKC $\delta$ in particular is known to participate in a number of cellular activities including cell proliferation, survival or apoptosis [195]. In addition to these structural and regulatory differences, PKC isoforms exhibit distinct patterns of tissue expression and subcellular localization, suggesting that these kinases might activate unique cell-specific functions [196]. It is therefore not unexpected to find that PKC isozymes are correlated to cancer in some way, although some isozymes have even been noted to both impede tumor formation and in other cancers promote tumor progression.

In breast cancer, the majority of research agrees that $\mathrm{PKC} \delta$ is involved in promoting tumor growth and development. As emphasized in one report illustrating that specific and selective down-regulation of PKC $\delta$ by shRNA was sufficient to prevent the growth of human breast and to inuce cytotoxicity [197] Alternatively, high expression of PRKCD, a variation of PKC, was correlated with poor patient survival in breast cancer [198]. Even though most of the research suggests similar findings, some studies claim that $\mathrm{PKC} \delta$ is not critical to tumor formation. One such study concludes that altered PKC $\delta$ expression does not seem to be a prerequisite for breast cancer progression [199]. Even more so another study observes that AD [198], a novel doxorubicin analog devoid of DNA binding and topoisomerase II inhibitory capacities, induces apoptosis by activating $\mathrm{PKC} \delta[200]$.

Therefore, because of these discrepancies it is vital to determine what causes the different effects of PKC $\delta$ expression, and whether these can be used as indicators to evaluate $\mathrm{PKC} \delta$ treatment effectiveness. While there is research claiming that $\mathrm{PKC} \delta$ isn't critical to tumor formation, there is little on the mechanism by which it achieves this. However, there are suggestions to how $\mathrm{PKC} \delta$ may promote tumor growth. One such report has identified a requirement for $\mathrm{PKC} \delta$ in ErbB2-driven proliferation of breast cancer cells [201]. Another indicates that in highly metastatic breast cancer cell lines (e.g., MDA-MB-231 and C3L5), expression of $\mathrm{PKC} \delta$ efficiently increases cell migration and invasion by inhibiting the small GTPase Cdc42 [202]. Regardless of the already made propositions, these suggestions should be reviewed and further analyzed to understand whether $\mathrm{PKC} \delta$ promotes or prevents tumor growth, how critical it is to tumor progression, and whether there are any indicators to predict outcome of treatments using PKC $\delta$ inhibitors. 


\subsection{PKA and cAMP Pathway Leads to Conflicting Events}

PKAs ability to phosphorylate depends on the presence and concentration of cAMP. PKA is the prime protein by which cAMP regulates and balances cellular processes. Although PKA is found in the ESR pathway, it impacts a multitude of signaling networks. Structurally PKA is a heterotetrameric kinase that can exist in two isoforms, type-I and type-II, depending on the isoform of the regulatory subunit associated with the holoenzyme [203]. After the regulatory subunits bind cAMP, the catalytic subunit can dissociate from the complex to phosphorylate its substrates [204]. The PKA type ratio is important as they function differently from one another leading to varied biological and cellular outcomes. In normal cells, while PKAI is transiently expressed at high levels in response to physiological or hormonal stimuli, PKA-II is preferentially expressed in differentiated tissues [205].

Similarly, to other genes in the ESR pathway, PKA has been associated with tumor development in breast cancer. Currently research emphasizes PKAs role in inhibiting tumor growth and accordingly may be a prospective avenue for cancer therapy. This is illustrated in a study which observes that cAMP/PKA signal pathway activation can reduce the proliferation of MCF-7 cells and play a crucial role in inhibiting the breast cancer progress [206]. One mechanism proposed is that melatonin regulation of $\mathrm{p} 38$ phosphorylation is mediated through Gi protein-induced changes in cAMP level and PKA activity since melatonin's effect on p 38 phosphorylation is attenuated by PKA inhibitor H89 [207]. Alternatively, some research suggests that PKA is involved in tumor growth and metastasis. PKA has been found to phosphorylate Src on serine-17 (S17) to regulate its activity and enhance tumor metastasis both in breast and ovarian tumors [208]. While others propose that under some circumstances, hCG may control breast cancer progression by combining the LH/hCGRs to activate the cAMP/PKA signaling pathway [209]. Therefore, it is evident that there is a significant need to improve our understanding of PKA to determine the cause of the discrepancies in its function on breast cancer development.

\subsection{PLC Variants Have Opposing Functions}

Phosphoinositide-dependent phospholipase C (PLC) are characterized by their catalytic activity in hydrolyzing phosphatidylinositol 4,5-bisphosphate forming the second messengers DAG and inositol 1,4,5-trisphosphate (IP3). By changing a second messenger concentration PLC can regulate numerous cellular processes simultaneously. However, it is important to note that there are 13 members to the PLC family each member containing 6 isozymes. Although all PLCs share common domains organized by the characteristic $\mathrm{X}-\mathrm{Y}$ catalytic domain, Pleckstrin homology domain (PH), EF-hand motifs, and C2 domain, they also have isozymespecific domain structures, differential expression patterns, and different cellular and physiological functions [210]. Because each PLC gene member and isozyme is unique, consequently making their function and regulation different from another, subsequently makes the construction of the crosstalk and path- 
ways complex. Moreover, some stimuli can activate and regulate different PLC isoenzymes simultaneously, which also complicates the understanding of the role of each single isoform [211]. The sheer number of functions exerted by the PLC reaction, made possible by the multitude of PLCs, demands its strict regulation and localization and its ability to respond to multiple extracellular and intracellular inputs with appropriate kinetics and absolute activities [212]. The multitude of PLC members and isoforms, although their balance is vital for healthy cells, have been associated with pathologies, however specific inhibition of PLC isoforms have not been fruitful.

Targeting specific PLC is particularly important because not all PLC are positively correlated to tumor progression in cancer, and because of their multitude of functions a broad inhibitor could cause cytotoxicity. The most researched isoform associated with breast cancer is PLC $\gamma 1$. The expression and activation levels of PLC $\gamma 1$ is correlated with distant metastases of early breast tumors [213]. This concurs with another study which suggests that PLC $\gamma 1$ is a main downstream target of PDK1 which promotes cancer cell invasion, however whether invasion is via invadopodia formation or ROCK1 activation or distinct processes involved in cell invasion remains to be investigated [214]. Therefore, these studies indicate that while PLC $\gamma 1$ is involved in metastases, the protein may not be required for cell growth and proliferation. As mentioned earlier, while it is agreed upon that PLC $\gamma 1$ participates in breast cancer metastasis, the exact mechanism and genes that are involved in this process is not fully understood. Some research indicates that the EGF-induced migration of MDA-HER2 breast cancer cells depends on PLC $\gamma 1$-PI3K crosstalk, which substantiate the interplay of EGFR/HER2 and HER2/HER3 heterodimer signaling [215]. However, other PLC genes and isoforms are relevant in breast cancer, specifically PLC $\beta 2$. Unlike PLC $\gamma 1$, PLC $\beta 2$ has been associated with negatively with invasion of breast cancer. This is illustrated in a study which indicates that in TNBC cells, the increased expression of PLC $\beta 2$ down-regulates invasiveness only in cells with high levels of CD133 since this PLC isozyme negatively modulates the expression of $\mathrm{CD} 133$, in turn involved in determining the invasive properties of CD133 highcells [216]. However, there has been much less research on PLC $\beta 2$ effect on breast cancer than there has been on PLC $\gamma 1$. Consequently it would be advantageous to observe the expressions and associations of these isoforms and other PLC alterations in breast cancer, especially when considering that broad targets of PLC will likely be ineffective.

\subsection{Oncogenes and Tumor Suppressors Regulate IP3R but Little Data on IP3}

Inositol 1,4,5-trisphosphate receptor (IP3R) comprise of three tetrameric protein subtypes IP3R1, IP3R2, and IP3R3 which act as intracellular channels for $\mathrm{Ca}^{2+}$. Each of the subtypes share high similarity $(70 \%-80 \%)$ in their primary sequences and are expressed to varying degrees in individual cell types [217]. 
Moreover, each subtype is constructed of an N-terminal ligand binding domain, an intervening modulatory domain, and a C-terminal transmembrane pore domain. IP3Rs are ubiquitously expressed and become activated by the second messenger IP3 [218]. IP3 is a soluble molecule that can diffuse through the cytoplasm until bound. While binding of IP3 generally promotes the opening of channels, the dependence on cytosolic $\mathrm{Ca}^{2+}$ is biphasic [219]. Although IP3Rs are a universal, main route for $\mathrm{Ca}^{2+}$ to pass membranes, there are other entry channels for $\mathrm{Ca}^{2+}$. $\mathrm{Ca}^{2+}$ release via such channels is one of the most ubiquitous and versatile cellular signaling mechanisms which regulates diverse physiological functions, including muscle contraction, fertilization, hormone secretion, gene transcription, metabolic regulation, immune responses, apoptosis, learning and memory [220].

Functions such as gene transcription, immune responses, and apoptosis indicate that the IP3R channel could be involved in cancer, along with numerous other pathologies. Indeed, IP3Rs have been reported to participate in the malignant phenotype breast cancer among a multitude of other cancers. It has been observed that expression level of IP3R3 is controlled by E2 in an estrogen receptor-dependent manner and that the growth of MCF-7 cells induced by E2 is sensitive to pharmacological inhibitors of IP3Rs [221]. Additionally, the report demonstrates that IP3R3 gene silencing using specific siRNA diminishes E2-induced cell growth and changed the temporal feature of ATP-induced intracellular $\mathrm{Ca}^{2+}$ signals. This result is confirmed by another report which observes that IP3R knockdown produced a 50\% decline in E2-ER $\alpha$-stimulated MCF-7 cell proliferation [222]. While it was not tested and examined in breast cancer it is interesting to note that IP3R mediates apoptosis by binding to BRCA1, a known tumor suppressor, and that loss of IP3R expression abolishes the recruitment of BRCA1 to the endoplasmic reticulum which facilitates apoptotic processes [223]. Generally in cancer, it would seem that proto-oncogenes cause reduced IP3R activity, whereas tumor suppressors' cause increased IP3R activity to regulate cell death [224]. However, none of these studies explain the expression levels of IP3R during breast cancer and while some associations with other proteins are observed it would be useful to explore other mechanisms and pathways. Without this information, it is not possible to predict all the effects of IP3R specific isoform inhibitors and which other inhibitors should be used in conjunction. Moreover, the ligand IP3 has not been associated with breast cancer and has not been thoroughly researched. It is therefore even more pertinent to explore IP3s regulation of its receptor.

\subsection{Meta-Analyses Limitations in Studying eNOS}

Although there are 3 different isoforms of nitric oxide synthases (NOSs), the endothelial nitric oxide synthases (eNOSs) are expressed in all types of cells and are the primary catalyst of nitric oxide (NO) in humans. Furthermore, eNOS is classified as "Constitutively expressed" and $\mathrm{Ca}^{2+}$ sensitive and typically associate 
with the plasma membrane or the golgi apparatus membrane [225]. The bi-domain enzyme comprises of a C-terminal reductase domain which binds nicotinamide adenine dinucleotide phosphate, the flavins mononucleotide, and flavin adenine dinucleotide; an N-terminal oxidase domain which binds heme, zinc, tetrahydrobiopterin, and CAM [226]. Additionally, the eNOS gene is located on chromosome 7 (7q36) and the protein is the rate limiting enzyme for NO production [227]. Consequently, this makes eNOS a critical molecule for the regulation of $\mathrm{NO}$ and therefore could be related to different pathologies.

Indeed, eNOS has been associated with cancer, including breast cancer. However, there has been much debate on which polymorphisms of eNOS are associated with breast cancer. Most studies involving eNOS conduct metaanalyses and although these studies are useful, they are not always reliable. Mainly, there can be individual biases within the works selected that can skew data. However, like any study, it is pertinent that there is a large collection of data in order to prevent significant skewing from outliers. The limitations of meta-analysis studies are emphasized by the disparity between such studies focused on eNOS. One study asserts that only the polymorphisms 786T and 894G were associated with breast cancer risk and the former was associated with the risk of tumor stage III and IV [228]. However, it must be noted that this study was specified to a Chinese Han population, and consequently could explain any discrepancies. As observed in another meta-analysis which indicates that $894 \mathrm{G}$ has no association with cancer susceptibility, however the $786 \mathrm{~T}$ polymorphism were associated with breast cancer risk [229]. The same study notes that some meta-analysis studies have used duplicated data and consequently could explain the inconsistancies in the literature, for instance in a study conducted by Zintzaras et al [230]. While there was agreement between 786T, there was no such agreement for 894G. Whether this was a difference in sample size, sample selection, bias, or region based is difficult to determine and consequently needs to be further explored and examined. One study even asserts that none of these polymorphisms have a role in increased or decreased risk of overall cancer [231]. However, the reason behind the discrepancy is clearer in this study, it is likely that because the meta-analysis was observing cancer as a whole it is possible that either the sample size o was too small or there might not have been thorough analysis for a pattern within subsets of breast cancer. Regardless of polymorphisms, it has been shown that, while using a breast cancer cell line, the inhibition of eNOS reduces tumor cell adhesion which facilitates tumor metastasis [232]. However, the research in this matter is lacking and consequently not only should there be further analysis on determining the polymorphisms association with breast cancer, but also on how eNOS effects breast cancer progression.

\subsection{MAPK Studies Observe Surprising Results}

The classic MAPK family consists of 4 subfamilies: ERKs, the c-Jun-N-terminal kinases (JNKs), the p38MAPKs and ERK-5 [233]. MAPKs in response to a diverse range of stimuli become activated, which is facilitated by MAPK kinases, 
enabling it to trigger cell apoptosis, proliferation, and differentiation. Activated MAPKs phosphorylate various substrate proteins including transcription factors such as Elk-1, c-Jun, ATF2, and p53 [234]. Inactivation is facilitated by the conserved MAPK phosphatases. Even though there are differences between the MAPK members, the ERK1 and ERK2 members differ more from one another in a given species more than either ERK1 or ERK2 differs among the three species [235]. Regardless, there has specifically been a lot of research investigating ERK1/2 and p38 MAPK, but there has been less on other proteins such as ERK7 (MAPK15).

While the majority of MAPK members seem to be positively correlated to tumor formation in breast cancer, some studies have detected tumor suppressor activities. One such study showed that knockdown of $\mathrm{p} 38$ in vivo was found to not only significantly increase tumor cell invasion and metastatic activity by upregulating expression of the epithelial-to-mesenchymal transition protein, vimentin, but also increased tumor metastasis by increasing tumor stromal tissue expansion [236]. Similarly another study shows that inhibition of cell proliferation induced by chlorpyrifos is an increment of p-ERK1/2 levels mediated by $\mathrm{H}_{2} \mathrm{O}_{2}$ in breast cancer cells [237]. Paradoxically, it was observed in two other reports using different methods, that activation of ERK1/2 leads to an up-regulation of anti-apoptotic proteins, such as the Bcl-2 family [238] [239]. Consequently this indicated that some other biological cues govern ERK1/2 activities on tumor development. Even though the MAPK family is thoroughly investigated in a multitude of cancers, the discrepancies between reports have explained in any research to date.

\subsection{Only Iindividual Components of AP1 Correlated to Breast Cancer}

The activator protein 1 (AP1) is a transcription factor that is composed of members of the Jun Proto-Oncogene (Jun) and FBJ Murine Osteosarcoma Viral Oncogene Homolog (Fos) protein families, all of which are involved in the healthy ESR pathway. Unlike the JUN family members (c-Jun, Jun-B, Jun-D), the FOS family members (c-Fos, Fra-1, Fra-2 and Fos-B) need to hetrodimerize with members of the JUN family to form transcriptionally active complexes [240]. Although Jun family members can interact within themselves making homodimers, Fos-Jun heterodimer interactions are more efficient at altering transcription. AP1 constituent proteins are structurally distinguished by a basic leucine zipper (bZIP) domain that is composed of leucine zipper and basic domains which function as binding sites for DNA [241]. Since there are multiple interactions that occur between AP1s constituent proteins, especially in regards to Fos, AP1 participates in numerous cellular functions including apoptosis, proliferation, growth, and differenti ation. Although these proteins have been correlated to other physiological pathologies, they are most evident and researched in cancer. 
There is a strong correlation between the individual members that make up the AP1 complex and breast cancer. One study specifically explores AP1s members in breast cancer and while there were correlations found between individual members, there was no overall positive or negative association between the AP1 complex with breast cancer [240]. They proposed that Jun-B was associated with less aggressive tumors and stated that c-Fos was less expressed in breast cancer tumors, whereas Fos-related antigen (Fra) 1 and 2, and Jun-D were overexpressed. While Fos was confirmed to be downregulated in one study [242], in another report c-Fos was involved in the upregulation of genes involved in positive regulation cell proliferation and the downregulation of genes involved in negative regulation of cell proliferation [243]. However, the discrepancy may be caused by the specific subset of breast cancer. Dahlman-Wright et al., observe this distinction particularly for ER $\alpha+$ while Ueno's et al. study focuses on all subsets of breast cancer.

Furthermore, another member known as Fra-1 has been specifically researched in regards to breast cancer even though Ueno et al found no clinical association with Fra-1. Regardless, one study proposes that the high accumulation of Fra- 1 is induced by the $\operatorname{PKC} \theta$ pathway and is critical to mediate the effect of this kinase on cell migration [244]. Moreover, Fra-1 has also been suspected in being involved with early events in carcinogenesis, as well as high grade tumors [245]. With that being said, most of these studies state that Fra-1 does not correlate to patient outcome and prognosis [242] [245] [246]. That is not to say that AP1 complex members do not effect patient outcome. Indeed, Fra-2 has been associated with metastatic breast cancer, early relapse, and poor prognosis most likely because of its influence on cell adhesion, especially during extravasation from the bloodstream [246]. Additionally, another protein in the AP1 complex has been associated with migration of breast cancer. Specifically c-Jun, which plays a key role in ErbB2-induced migration and invasion of mammary epithelial cells via the production of CCL5 and stem cell factor (SCF) [247]. Taken together, these results show many discrepancies between members of the AP1 complex with breast cancer risk and prognosis, consequently, it is critical to further analyze these genes in order to facilitate drug therapy development.

\section{Future Directions}

While many of these genes have been thoroughly investigated and are well established in regards to breast cancer, some of these genes have been either overlooked or there remain inconsistencies within the literature. Therefore, there are prospective studies that could be undergone to explain any discrepancies found and/or to validate the presence and associations of the proteins in breast cancer. One such protein that could be re-evaluated is MMP. While there is a general understanding of MMP function in breast cancer, there are discrepancies regarding the variations of MMP present in breast cancer. MMPs have been associated with multiple different proteins, such as HBEGF and CREB, and conse- 
quently it would be useful to further investigate and confirm such associations.

One route of study could be by conducting gene expression data analysis on publicly available and real patient breast cancer datasets. This could potentially be useful in determining co-expression patterns of ESR pathway genes involved in breast cancer. For such study, it is imperative to have a large collection of data, to predict significant results not skewed by outliers. While many of these studies are reliable and analyze a large collection of data samples, other reports require more data. Online public repositories of breast cancer datasets are not only easily accessible but contain a vast amount of data and thus can be useful for examining correlations. However, some limitations exist with public datasets, predominantly involving missing information and the lack of temporal based data.

Gene expression analysis by applying clustering methods, such as hierarchical clustering (HC) and self-organizing map (SOM) could be beneficial in understanding the co-expression patterns of the genes in breast cancer samples/datasets. Although there are limitations to both studies, consensus clustering (CC) could be applied to validate and improve reliability of results. Limitations of SOM and HC include sensitivity to outliers, comparing studies, and visual representations [248]. However, these studies could not only determine gene expression levels, but also assort co-expression data which can indicate interrelatedness between genes and function. Integrated structural study, as mentioned in the introduction section, can be further used to decipher the gene network dynamics in breast cancer. Particularly, this could be useful for genes such as MMP where there are disagreements on isoform presence. Moreover, the data suggest relations with other proteins such as Src and CREB, which could be validated or illustrate new associations through the application of HC, SOM and CC methods. Another protein that could be elucidated on by clustering methods is Raf; while it is generally well studied, the isoform ARaf has not been investigated. While these methods do not indicate prognosis or the exact functions of the proteins, fundamentals such as presence and co-expressions are vital for determining and developing a mutated ESR pathway.

However, these are not the only avenues of research that could benefit the medical community. Despite the plethora of articles published on the ESR pathway alone, there are discrepancies and areas of study that are still lacking. In order to build a comprehensive understanding of breast cancer to treat the disease, these regions of study should be explored by applying diverse methods. Followed by clustering methods and co-expression pattern analysis, structural analysis using molecular modeling and molecular dynamics can be used to model and understand the effect of mutations in the interactions between proteins-the products of genes, xenotransplantation methods which enable in vivo study of tumors sensitivity to inhibitors and cancer therapy, meta-analyses to consolidate findings and can mitigate discrepancies. For instance, while meta-analyses have been thoroughly applied to eNOS, they have not been applied to other 
genes/proteins which could be efficacious to explore. Consequently, even though much has been determined in the analysis and study of breast cancer, there is still much more to explore and will surely be efficacious in treating the aggressive disease that affects so many women worldwide.

\section{Acknowledgements}

This publication was made possible by NPRP 7-1083-1-191 from the Qatar National Research Fund (a member of the Qatar Foundation). The statements made herein are solely the responsibility of the authors.

\section{References}

[1] Siegel, R.L., Miller, K.D. and Jemal, A. (2016) Cancer Statistics. CA: A Cancer Journal for Clinicians, 66, 7-30. https://doi.org/10.3322/caac.21332

[2] Youlden, D.R., Cramb, S.M., Yip, C.H. and Baade, P.D. (2014) Incidence and Mortality of Female Breast Cancer in the Asia-Pacific Region. Cancer Biology \& Medicine, 11, 101-115.

[3] Saha Roy, S. and Vadlamudi, R.K. (2012) Role of Estrogen Receptor Signaling in Breast Cancer Metastasis. International Journal of Breast Cancer, 2012, Article ID: 654698. https://doi.org/10.1155/2012/654698

[4] Pechkova, E., Bragazzi, N., Bozdaganyan, M., Belmonte, L. and Nicolini, C. (2014) A Review of the Strategies for Obtaining High-Quality Crystals Utilizing Nanotechnologies and Microgravity. Critical Reviews in Eukaryotic Gene Expression, 24, 325-339. https://doi.org/10.1615/CritRevEukaryotGeneExpr.2014008275

[5] Chitrala, K.N. and Yeguvapalli, S. (2014) Computational Screening and Molecular Dynamic Simulation of Breast Cancer Associated Deleterious Non-Synonymous Single Nucleotide Polymorphisms in TP53 Gene. PLoS ONE, 9, e104242. https://doi.org/10.1371/journal.pone.0104242

[6] Ozbligin, K., Karaca, F., Turan, A., Kose, C., Vatansever, S. and Ozcakir, T. (2015) The Higher Heparin-Binding Epidermal Growth Factor (HB-EGF) in Missed Abortion. Taiwanese Journal of Obstetrics and Gynecology, 54, 13-18. https://doi.org/10.1016/j.tjog.2013.08.011

[7] Vinante, F. and Rigo, A. (2013) Heparin-Binding Epidermal Growth Factor-Like Growth Factor/Diphtheria Toxin Receptor in Normal and Neoplastic Hematopoiesis. Toxins, 5, 1180-1201. https://doi.org/10.3390/toxins5061180

[8] Sato, S., Drake, A.W., Tsuji, I. and Fan, J. (2012) Apotent Anti-HB-EGF Monoclonal Antibody Inhibits Cancer Cell Proliferation and Multiple Angio-Genic Activities of HB-EGF. PLoS ONE, 7, e51964. https://doi.org/10.1371/journal.pone.0051964

[9] Zhou, Z.N., Sharma, V.P., Beaty, B.T., et al. (2014) Autocrine HBEGF Expression Promotes Breast Cancer Intravasation, Metastasis and Macrophage-Independent Invasion in Vivo. Oncogene, 33, 3784-3793. https://doi.org/10.1038/onc.2013.363

[10] Eccles, S.A. (2011) The Epidermal Growth factor Receptor/Erb-B/HER Family in Normal and Malignant Breast Biology. The International Journal of Developmental Biology, 55, 685-696. https://doi.org/10.1387/ijdb.113396se

[11] Burness, M.L., Grushko, T.A. and Olopade, O.I. (2010) Epidermal Growth Factor Receptor in Triplenegative and Basal-Like Breast Cancer: Promising Clinical Target or Only a Marker? The Cancer Journal, 16, 23-32. https://doi.org/10.1097/PPO.0b013e3181d24fc1 
[12] Secq, V., Villeret, J., Fina, F., Carmassi, M., Carcopino, X., Garcia, S., et al. (2014) Triple Negative Breast Carcinoma EGFR Amplification Is Not Associated with EGFR, Kras or ALK Mutations. British Journal of Cancer, 110, 1045-1052. https://doi.org/10.1038/bjc.2013.794

[13] Jin, Q. and Esteva, F.J. (2008) Cross-Talk between the ErbB/HER Family and the Type I Insulin-Like Growth Factor Receptor Signaling Pathway in Breast Cancer. Journal of Mammary Gland Biology and Neoplasia, 13, 485-498. https://doi.org/10.1007/s10911-008-9107-3

[14] Zhang, C. and Sarkar, D.K. (2012) $\beta$-Endorphin Neuron Transplantation: A Possible Novel Therapy for Cancer Prevention. Oncoimmunology, 1, 552-554. https://doi.org/10.4161/onci.19335

[15] Sloan, E.K., Priceman, S.J., Cox, B.F., et al. (2010) Sympathetic Nervous System Induces a Metastatic Switch in Primary Breast Cancer. Cancer Research, 70, 7042-7052. https://doi.org/10.1158/0008-5472.CAN-10-0522

[16] Sarkar, D.K., Zhang, C., Murugan, S., Dokur, M., Boyadjieva, N.I., Ortiguela, M., et al. (2011) Transplantation of $\beta$-Endorphin Neurons into the Hypothalamus Promotes Immune Function and Restricts the Growth and Metastasis of Mammary Carcinoma. Cancer Research, 71, 6282-6291. https://doi.org/10.1158/0008-5472.CAN-11-1610

[17] Benke, D. (2010) Mechanisms of GABAB Receptor Exocytosis, Endocytosis, and Degradation. Advances in Pharmacology, 58, 93-111. https://doi.org/10.1016/S1054-3589(10)58004-9

[18] Pinard, A., Seddik, R. and Bettler, B. (2010) GABAB Receptors: Physiological Functions and Mechanisms of Diversity. Advances in Pharmacology, 58, 231-255. https://doi.org/10.1016/S1054-3589(10)58010-4

[19] Luscher, C. and Slesinger, P.A. (2010) Emerging Roles for G Protein-Gated Inwardly Rectifying Potassium (GIRK) Channels in Health and Disease. Nature Reviews Neuroscience, 11, 301-315. https://doi.org/10.1038/nrn2834

[20] Jiang, X., Su, L., Zhang, Q., He, C., Zhang, Z., Yi, P. and Liu, J. (2012) GABAB Receptor Complex as a Potential Target for Tumor Therapy. Journal of Histochemistry \& Cytochemistry, 60, 269-279. https://doi.org/10.1369/0022155412438105

[21] Shu, Q., Liu, J., Liu, X., Zhao, S., Li, H., Tan, Y. and Xu, J. (2016) GABABR/GSK- $3 \beta /$ NF- $\kappa$ B Signaling Pathway Regulates the Proliferation of Colorectal Cancer Cells. Cancer Medicine, 5, 1259-1267. https://doi.org/10.1002/cam4.686

[22] Cooper, A., Grigoryan, G., Guy-David, L., Tsoory, M.M., Chen, A. and Reuveny, E. (2012) Trisomy of the G Protein-Coupled K+ Channel Gene, Kcnj6, Affects Reward Mechanisms, Cognitive Functions, and Synaptic Plasticity in Mice. Proceedings of the National Academy of Sciences of the United States of America, 109, 2642-2647. https://doi.org/10.1073/pnas.1109099109

[23] Jiang, X., Su, L., Zhang, Q., et al. (2012) GABAB Receptor Complex as a Potential Target for Tumor Therapy. Journal of Histochemistry \& Cytochemistry, 60, 269-279. https://doi.org/10.1369/0022155412438105

[24] Geng, Y., Bush, M. and Fan, Q.R. (2013) Structural Mechanism of Ligand Activation in Human GABA(B) Receptor. Nature, 504, 254-259. https://doi.org/10.1038/nature12725

[25] Rezania, S., Li, C., Kammerer, S., Gorischek, A., Devaney, T., Zarnani, A.H., Baeuernhofer, T. and Schreibmayer, W. (2014) G-Protein Activated Inwardly Rectifying Potassium Channels Control Motility of Breast Cancer Cells. Biophysical 
Journal, 106, 543. https://doi.org/10.1016/j.bpj.2013.11.3026

[26] Seebahn, A., Sticht, H. and Enz, R. (2013) Expression, Purification, and Structural Analysis of Intracellular C-Termini from Metabotropic Glutamate Receptors. $\mathrm{Me}$ thods in Enzymology, 520, 257-279. https://doi.org/10.1016/B978-0-12-391861-1.00012-5

[27] Willard, S.S. and Koochekpour, S. (2013) Glutamate Signaling in Benign and Malignant Disorders: Current Status, Future Perspectives, and Therapeutic Implications. International Journal of Biological Sciences, 9, 728-742. https://doi.org/10.7150/ijbs.6475

[28] Esseltine, J.L., Ribeiro, F.M. and Ferguson, S.S. (2012) Rab8 Modulates Metabotropic Glutamate Receptor Subtype 1 Intracellular Trafficking and Signaling in a Protein Kinase C-Dependent Manner. Journal of Neuroscience, 32, 16933-16942. https://doi.org/10.1523/JNEUROSCI.0625-12.2012

[29] Esseltine, J.L., Willard, M.D., Wulur, I.H., et al. (2013) Somatic Mutations in GRM1 in Cancer Alter Metabotropic Glutamate Receptor 1 Intracellular Localization and Signaling. Molecular Pharmacology, 83, 770-780.

https://doi.org/10.1124/mol.112.081695

[30] Speyer, C.L., Smith, J.S., Banda, M., DeVries, J.A., Mekani, T. and Gorski, D.H. (2012) Metabotropic Glutamate Receptor-1: A Potential Therapeutic Target for the Treatment of Breast Cancer. Breast Cancer Research and Treatment, 132, 565-573. https://doi.org/10.1007/s10549-011-1624-x

[31] Banda, M., Speyer, C.L., Semma, S.N., et al. (2014) Metabotropic Glutamate Receptor-1 Contributes to Progression in Triple Negative Breast Cancer. PLoS ONE, 9 , e81126. https://doi.org/10.1371/journal.pone.0081126

[32] Speyer, C.L., Hachem, A.H., Assi, A.A., Johnson, J.S., DeVries, J.A. and Gorski, D.H. (2014) Metabotropic Glutamate Receptor-1 as a Novel Target for the Antiangiogenic Treatment of Breast Cancer. PLoS ONE, 9, e88830. https://doi.org/10.1371/journal.pone.0088830

[33] Sen, B. and Johnson, F.M. (2011) Regulation of SRC Family Kinases in Human Cancers. Journal of Signal Transduction, 2011, Article ID: 865819. https://doi.org/10.1155/2011/865819

[34] Banerjee, M., Duan, Q. and Xie, Z. (2015) SH2 Ligand-Like Effects of Second Cytosolic Domain of Na/K-ATPase $\alpha 1$ Subunit on Src Kinase. PLoS ONE, 10, e0142119. https://doi.org/10.1371/journal.pone.0142119

[35] Fan, P., McDaniel, R.E., Kim, H.R., Clagett, D., Haddad, B. and Jordan, V.C. (2012) Modulating Therapeutic Effects of the c-Src Inhibitor via Estrogen Receptor and HER2 in Breast Cancer Cell Lines. European Journal of Cancer, 48, 3488-3498. https://doi.org/10.1016/j.ejca.2012.04.020

[36] Thakur, R., Trivedi, R., Rastogi, N., Singh, M. and Mishra, D.P. (2015) Inhibition of STAT3, FAK and Src Mediated Signaling Reduces Cancer Stem Cell Load, Tumorigenic Potential and Metastasis in Breast Cancer. Scientific Reports, 5, Article No. 10194. https://doi.org/10.1038/srep10194

[37] Zhang, S., Huang, W.C., Li, P., et al. (2011) Combating Trastuzumab Resistance by Targeting SRC, a Common Node Downstream of Multiple Resistance Pathways. Nature Medicine, 17, 461-469. https://doi.org/10.1038/nm.2309

[38] Rexer, B.N., Ham, A.J., Rinehart, C., et al. (2011) Phosphoproteomic Mass Spectrometry Profiling Links Src Family Kinases to Escape from HER2 Tyrosine Kinase Inhibition. Oncogene, 30, 4163-4174. https://doi.org/10.1038/onc.2011.130 
[39] Elsberger, B. (2014) Translational Evidence on the Role of Src Kinase and Activated Src Kinase in Invasive Breast Cancer. Critical Reviews in Oncology/ Hematology, 89, 343-351. https://doi.org/10.1016/j.critrevonc.2013.12.009

[40] Formisano, L., Nappi, L., Rosa, R., et al. (2014) Epidermal Growth Factor-Receptor Activation Modulates Src-Dependent Resistance to Lapatinib in Breast Cancer Models. Breast Cancer Research: BCR, 16, R45. https://doi.org/10.1186/bcr3650

[41] Liu, Z., Zhang, J., Wu, L., Liu, J. and Zhang, M. (2014) Overexpression of GNAO1 Correlates with Poor Prognosis in Patients with Gastric Cancer and Plays a Role in Gastric Cancer Cell Proliferation and Apoptosis. International Journal of Molecular Medicine, 33, 589-596. https://doi.org/10.3892/ijmm.2013.1598

[42] El-Haibi, C.P., Sharma, P., Singh, R., et al. (2013) Differential G Protein Sub-Unit Expression by Prostate Cancer Cells and Their Interaction with CXCR5. Molecular Cancer, 12, 64. https://doi.org/10.1186/1476-4598-12-64

[43] Urtatiz, O. and Van Raamsdonk, C.D. (2016) Gnaq and Gna11 in the Endothelin Signaling Pathway and Melanoma. Frontiers in Genetics, 7, 59. https://doi.org/10.3389/fgene.2016.00059

[44] Kan, Z., Jaiswal, B.S., Stinson, J., et al. (2010) Diverse Somatic Mutation Patterns and Pathway Alterations in Human Cancers. Nature, 466, 869-873.

https://doi.org/10.1038/nature09208

[45] Bollig-Fischer, A., Michelhaugh, S.K., Wijesinghe, P., et al. (2015) Cytogenomic Profiling of Breast Cancer Brain Metastases Reveals Potential for Repurposing Targeted Therapeutics. Oncotarget, 6, 14614-14624.

https://doi.org/10.18632/oncotarget.3786

[46] Garcia-Murillas, I., Sharpe, R., Pearson, A., et al. (2014) An siRNA Screen Identifies the GNAS Locus as a Driver in 20q Amplified Breast Cancer. Oncogene, 33, 2478-2486. https://doi.org/10.1038/onc.2013.202

[47] Yagi, H., et al. (2011) A Synthetic Biology Approach Reveals a CXCR4-G13-Rho Signaling Axis Driving Transendothelial Migration of Metastatic Breast Cancer Cells. Science Signaling, 4, ra60. https://doi.org/10.1126/scisignal.2002221

[48] Ahmed, Z., Timsah, Z., Suen, K.M., et al. (2015) Grb2 Monomer-Dimer Equilibrium Determins Normal versus Oncogenic Function. Nature Communications, 6, 8007. https://doi.org/10.1038/ncomms9007

[49] Lin, C.C., Melo, F.A., Ghosh, R., et al. (2012) Inhibition of Basal FGF Receptor Signaling by Dimeric Grb2. Cell, 149, 1514-1524.

https://doi.org/10.1016/j.cell.2012.04.033

[50] Yin, J., Cai, Z., Zhang, L., et al. (2013) A Recombined Fusion Protein PTD-Grb2-SH2 Inhibits the Proliferation of Breast Cancer Cells in Vitro. International Journal of Oncology, 42, 1061-1069. https://doi.org/10.3892/ijo.2013.1768

[51] Ahmed, Z., Lin, C.-C., Suen, K.M., et al. (2013) Grb2 Controls Phosphorylation of FGFR2 by Inhibiting Receptor Kinase and Shp2 Phosphatase Activity. The Journal of Cell Biology, 200, 493-504. https://doi.org/10.1083/jcb.201204106

[52] Bisson, N., James, D.A., Ivosev, G., et al. (2011) Selected Reaction Monitoring Mass Spectrometry Reveals the Dynamics of Signaling through the GRB2 Adaptor. Nature Biotechnology, 29, 653-658. https://doi.org/10.1038/nbt.1905

[53] Luey, B.C. and May, F.E.B. (2016) Insulin-Like Growth Factors Are Essential to Prevent Anoikis in Oestrogen-Responsive Breast Cancer Cells: Importance of the Type I IGF Receptor and PI3-Kinase/Akt Pathway. Molecular Cancer, 15, 8. https://doi.org/10.1186/s12943-015-0482-2 
[54] Zhang, Y., Xu, G., Liu, G., et al. (2016) miR-411-5p Inhibits Proliferation and Metastasis of Breast Cancer Cell via Targeting GRB2. Biochemical and Biophysical Research Communications.

[55] Davies, M.A. (2011) Regulation, Role, and Targeting of Akt in Cancer. Journal of Clinical Oncology, 29, 4715-4717. https://doi.org/10.1200/JCO.2011.37.4751

[56] Diez, H., Garrido, J.J. and Wandosell, F. (2012) Specific Roles of Akt Iso Forms in Apoptosis and Axon Growth Regulation in Neurons. PLOS ONE, 7, e32715. https://doi.org/10.1371/journal.pone.0032715

[57] Liu, W., Bagaitkar, J. and Watabe, K. (2007) Roles of Akt Signal in Breast Cancer. Frontiers in Bioscience, 12, 4011-4019. https://doi.org/10.2741/2367

[58] Fabi, F. and Asselin, E. (2014) Expression, Activation, and Role of AKT Isoforms in the Uterus. Reproduction, 148, R85-R95. https://doi.org/10.1530/REP-14-0270

[59] Fox, E.M., Kuba, M.G., Miller, T.W., Davies, B.R. and Arteaga, C.L. (2013) Autocrine IGF-I/Insulin Receptor Axis Compensates for Inhibition of AKT in ER-Positive Breast Cancer Cells with Resistance to Estrogen Deprivation. Breast Cancer Research: BCR, 15, R55. https://doi.org/10.1186/bcr3449

[60] Paplomata, E., Zelnak, A. and O’Regan, R. (2013) Everolimus: Side Effect Profile and Management of Toxicities in Breast Cancer. Breast Cancer Research and Treatment, 140, 453-462. https://doi.org/10.1007/s10549-013-2630-y

[61] Wong, C., Wang, X., Smith, D., Reddy, K. and Chen, S. (2012) AKT-Aro and HER2-Aro, Models for De Novo Resistance to Aromatase Inhibitors, Molecular Characterization and Inhibitor Response Studies. Breast Cancer Research and Treatment, 134, 671-681. https://doi.org/10.1007/s10549-012-2105-6

[62] O’Hurley, G., Daly, E., O’Grady, A., et al. (2014) Investigation of Molecular Alterations of AKT-3 in Triple-Negative Breast Cancer. Histopathology, 64, 660-670. https://doi.org/10.1111/his.12313

[63] Fernandez-Medarde, A. and Santos, E. (2011) Ras in Cancer and Developmental Diseases. Genes \& Cancer, 2, 344-358. https://doi.org/10.1177/1947601911411084

[64] Myers, M.B., Banda, M., McKim, K.L., Wang, Y., Powell, M.J. and Parsons, B.L. (2016) Breast Cancer Heterogeneity Examined by High-Sensitivity Quantification of PIK3CA, KRAS, HRAS, and BRAF Mutations in Normal Breast and Ductal Carcinomas. Neoplasia, 18, 253-263. https://doi.org/10.1016/j.neo.2016.03.002

[65] Giltnane, J.M. and Balko, J.M. (2014) Rationale for Targeting the Ras/MAPK Pathway in Triple-Negative Breast Cancer. Discovery Medicine, 17, 275-283.

[66] Niemitz, E. (2013) Ras Pathway Activation in Breast Cancer. Nature Genetics, 45, 1273. https://doi.org/10.1038/ng.2817

[67] Sanchez-Munoz, A., Gallego, E., de Luque, V., et al. (2010) Lack of Evidence for KRAS Oncogenic Mutations in Triple-Negative Breast Cancer. BMC Cancer, 10, 136. https://doi.org/10.1186/1471-2407-10-136

[68] Grob, T.J., Heilenkotter, U., Geist, S., et al. (2012) Rare Oncogenic Mutations of Predictive Markers for Targeted Therapy in Triple-Negative Breast Cancer. Breast Cancer Research and Treatment, 134, 561-567. https://doi.org/10.1007/s10549-012-2092-7

[69] Pereira, C.B., Leal, M.F., De Souza, C.R., et al. (2013) Prognostic and Predictive Significance of MYC and KRAS Alterations in Breast Cancer from Women Treated with Neoadjuvant Chemotherapy. PLoS ONE, 8, e60576. https://doi.org/10.1371/journal.pone.0060576

[70] Paranjape, T., Heneghan, H., Lindner, R., et al. (2011) A 3t-Untranslated Region 
KRAS Variant and Triple-Negative Breast Cancer: A Case-Control and Genetic Analysis. The Lancet Oncology, 12, 377-386. https://doi.org/10.1016/S1470-2045(11)70044-4

[71] Jancik, S., Drabek, J., Radzioch, D. and Hajduch, M. (2010) Clinical Relevance of KRAS in Human Cancers. Journal of Biomedicine and Biotechnology, 2010, Article ID: 150960. https://doi.org/10.1155/2010/150960

[72] Zheng, Z.Y., Tian, L., Bu, W., et al. (2015) Wild Type N-Ras, Overexpressed in Basal-Like Breast Cancer, Promotes Tumor Formation by Inducing IL8 Secretion via JAK2 Activation. Cell Reports, 12, 511-524. https://doi.org/10.1016/j.celrep.2015.06.044

[73] Yong, H.Y., Hwang, J.S., Son, H., et al. (2011) Identification of H-Ras-Specific Motif for the Activation of Invasive Signaling Program in Human Breast Epithelial Cells. Neoplasia, 13, 98-107. https://doi.org/10.1593/neo.101088

[74] De, S., Dermawan, J.K.T. and Stark, G.R. (2014) EGF Receptor Uses SOS1 to Drive Constitutive Activation of $\mathrm{NF} \kappa \mathrm{B}$ in Cancer Cells. Proceedings of the National Academy of Sciences of the United States of America, 111, 11721-11726. https://doi.org/10.1073/pnas.1412390111

[75] Denayer, E., Devriendt, K., De Ravel, T., et al. (2010) Tumor Spectrum in Children with Noonan Syndrome and SOS1 or RAF1 Mutations. Genes Chromosomes Cancer, 49, 242-252.

[76] Rojas, J.M., Oliva, J.L. and Santos, E. (2011) Mammalian Son of Sevenless Guanine Nucleotide Exchange Factors: Old Concepts and New Perspectives. Genes \& Cancer, 2, 298-305. https://doi.org/10.1177/1947601911408078

[77] Pierre, S., Bats, A.S. and Coumoul, X. (2011) Understanding SOS (Son of Sevenless). Biochemical Pharmacology, 82, 1049-1056. https://doi.org/10.1016/j.bcp.2011.07.072

[78] Field, L.A., Love, B., Devarmin, B., Hooke, J.A., Shriver, C.D. and Ellsworth, R.E. (2012) Identification of Differentially Expressed Genes in Breast Tumors from African American Compared with Caucasian Women. Cancer, 118, 1334-1344. https://doi.org/10.1002/cncr.26405

[79] Boyle, P. (2012) Triple-Negative Breast Cancer: Epidemiological Considerations and Recommendations. Annals of Oncology, 23, vi7-vi12. https://doi.org/10.1093/annonc/mds187

[80] Rosse, C., Linch, M., Kermorgant, S., Cameron, A.J., Boeckeler, K. and Parker, P.J. (2010) PKC and the Control of Localized Signal Dynamics. Nature Reviews Molecular Cell Biology, 11, 103-112. https://doi.org/10.1038/nrm2847

[81] Urtreger, A.J., Kazanietz, M.G. and Bal de Kier Joffe, E.D. (2012) Contribution of Individual PKC Isoforms to Breast Cancer Progression. IUBMB Life, 64, 18-26. https://doi.org/10.1002/iub.574

[82] Evans, L.M., Cowey, S.L., Siegal, G.P. and Hardy, R.W. (2009) Stearate Preferentially Induces Apoptosis in Human Breast Cancer Cells. Nutrition and Cancer, 61, 746-753. https://doi.org/10.1080/01635580902825597

[83] Debald, M., Franken, S., Heukamp, L.C., et al. (2011) Identification of Specific Nuclear Structural Protein Alterations in Human Breast Cancer. Journal of Cellular Biochemistry, 112, 3176-3184. https://doi.org/10.1002/jcb.23249

[84] Yokokura, S., Yurimoto, S., Matsuoka, A., et al. (2014) Calmodulin Antagonists Induce Cell Cycle Arrest and Apoptosis in Vitro and Inhibit Tumor Growth in Vivo in Human Multiple Myeloma. BMC Cancer, 14, 882.

https://doi.org/10.1186/1471-2407-14-882 
[85] Berchtold, M.W. and Villalobo, A. (2014) The Many Faces of Calmodulin in Cell Proliferation, Programmed Cell Death, Autophagy, and Cancer. Biochimica et Biophysica Acta, 1843, 398-435. https://doi.org/10.1016/j.bbamcr.2013.10.021

[86] Fancy, R.M., Wang, L., Zeng, Q., et al. (2016) Characterization of the Interactions between Calmodulin and Death Receptor 5 in Triple-Negative and Estrogen Receptor-Positive Breast Cancer Cells: An Integrated Experimental and Computational Study. The Journal of Biological Chemistry, 291, 12862-12870.

https://doi.org/10.1074/jbc.M116.727727

[87] Debald, M., Schildberg, F.A., Linke, A., et al. (2013) Specific Expression of K63-Linked Ubiquitination of Calmodulin-Like Protein 5 in Breast Cancer of Premenopausal Patients. Journal of Cancer Research and Clinical Oncology, 139, 2125-2132. https://doi.org/10.1007/s00432-013-1541-y

[88] White, C.D., Li, Z. and Sacks, D.B. (2011) Calmodulin Binds HER2 and Modulates HER2 Signaling. Biochimica et Biophysica Acta, 1813, 1074-1082. https://doi.org/10.1016/j.bbamcr.2010.12.016

[89] Samatar, A.A. and Poulikakos, P.I. (2014) Targeting RAS-ERK Signaling in Cancer: Promises and Challenges. Nature Reviews Drug Discovery, 13, 928-942. https://doi.org/10.1038/nrd4281

[90] Matallanas, D., Birtwistle, M., Romano, D., et al. (2011) Raf Family Kinases: Old Dogs Have Learned New Tricks. Genes \& Cancer, 2, 232-260. https://doi.org/10.1177/1947601911407323

[91] An, S., Yang, Y., Ward, R., Liu, Y., Guo, X.X. and Xu, T.R. (2015) Raf-Interactome in Tuning the Complexity and Diversity of Raf Function. The FEBS Journal, 282, 32-53. https://doi.org/10.1111/febs.13113

[92] Santarpia, L., Qi, Y., Stemke-Hale, K., et al. (2012) Mutation Profiling Identifies Numerous Rare Drug Targets and Distinct Mutation Patterns in Different Clinical Subtypes of Breast Cancers. Breast Cancer Research and Treatment, 134, 333-343. https://doi.org/10.1007/s10549-012-2035-3

[93] Yang, G., Wu, D., Zhu, J., et al. (2013) Upregulation of miR-195 Increases the Sensitivity of Breast Cancer Cells to Adriamycin Treatment through Inhibition of Raf-1. Oncology Reports, 30, 877-889. https://doi.org/10.3892/or.2013.2532

[94] Glenisson, M., Vacher, S., Callens, C., et al. (2012) Identification of New Candidate Therapeutic Target Genes in Triple-Negative Breast Cancer. Genes \& Cancer, 3, 63-70. https://doi.org/10.1177/1947601912449832

[95] Chang, C.-J., Yang, J.-Y., Xia, W., et al. (2011) EZH2 Promotes Expansion of Breast Tumor Initiating Cells through Activation of RAF1- $\beta$-Catenin Signaling. Cancer Cell, 19, 86-100. https://doi.org/10.1016/j.ccr.2010.10.035

[96] Saini, K.S., Loi, S., De Azambuja, E., et al. (2013) Targeting the PI3K/AKT/mTOR and Raf/MEK/ERK Pathways in the Treatment of Breast Cancer. Cancer Treatment Reviews, 39, 935-946. https://doi.org/10.1016/j.ctrv.2013.03.009

[97] Ozel, C., Seidel, J., Meyer-Staeckling, S., et al. (2012) Hybrid Cells Derived from Breast Epithelial Cell/Breast Cancer Cell Fusion Events Show a Differential RAF-AKT Crosstalk. Cell Communication and Signaling: CCS, 10, 10. https://doi.org/10.1186/1478-811X-10-10

[98] Yi, T., Zhai, B., Yu, Y., et al. (2014) Quantitative Phosphoproteomic Analysis Reveals System-Wide Signaling Pathways Downstream of SDF-1/CXCR4 in Breast Cancer Stem Cells. Proceedings of the National Academy of Sciences of the United States of America, 111, E2182-E2190. https://doi.org/10.1073/pnas.1404943111

[99] Akinleye, A., Furqan, M., Mukhi, N., Ravella, P. and Liu, D. (2013) MEK and the 
Inhibitors: From Bench to Bedside. Journal of Hematology \& Oncology, 6, 27. https://doi.org/10.1186/1756-8722-6-27

[100] Roskoski, R. (2012) ERK1/2 MAP Kinases: Structure, Function and Regulation. Pharmacological Research, 66, 105-143. https://doi.org/10.1016/j.phrs.2012.04.005

[101] Zhao, Y. and Adjei, A.A. (2014) The Clinical Development of MEK Inhibitors. Nature Reviews Clinical Oncology, 11, 385-400. https://doi.org/10.1038/nrclinonc.2014.83

[102] Maiello, M.R., D’Alessio, A., Bevilacqua, S., Gallo, M., Normanno, N. and De Luca, A. (2015) EGFR and MEK Blockade in Triple Negative Breast Cancer Cells. Journal of Cellular Biochemistry, 116, 2668-2685. https://doi.org/10.1002/jcb.25220

[103] Kim, S., Lee, J., Jeon, M., Lee, J.E. and Nam, S.J. (2016) MEK-Dependent IL-8 Induction Regulated the Invasiveness of Triple-Negative Breast Cancer Cells. Tumor Biology, 37, 4991-4999. https://doi.org/10.1007/s13277-015-4345-7

[104] Storer, C.L., Dickey, C.A., Galigniana, M.D., Rein, T. and Cox, M.B. (2011) FKBP51 and FKBP52 in Signaling and Disease. Trends in Endocrinology and Metabolism: TEM, 22, 481-490. https://doi.org/10.1016/j.tem.2011.08.001

[105] Sivils, J.C., Storer, C.L., Galigniana, M.D. and Cox, M.B. (2011) Regulation of Steroid Hormone Receptor Function By the 52-kDa FK506-Binding Protein (FKBP52). Current Opinion in Pharmacology, 11, 314-319. https://doi.org/10.1016/j.coph.2011.03.010

[106] Wang, L. (2011) FKBP51 Regulation of AKT/Protein Kinase B Phosphorylation. Current Opinion in Pharmacology, 11, 360-364. https://doi.org/10.1016/j.coph.2011.03.008

[107] Li, L., Lou, Z. and Wang, L. (2011) The Role of FKBP5 in Cancer Aetiology and Chemoresistance. British Journal of Cancer, 104, 19-23.

https://doi.org/10.1038/sj.bjc.6606014

[108] Jirawatnotai, S., Sharma, S., Michowski, W., et al. (2014) The Cyclin D1-CDK4 Oncogenic Interactome Enables Identification of Potential Novel Oncogenes and Clinical Prognosis. Cell Cycle, 13, 2889-2900. https://doi.org/10.4161/15384101.2014.946850

[109] Bhushan, L. and Kandpal, R.P. (2011) EphB6 Receptor Modulates Micro RNA Profile of Breast Carcinoma Cells. PLoS ONE, 6, e22484.

https://doi.org/10.1371/journal.pone.0022484

[110] Yang, W.S., Moon, H.G., Kim, H.S., et al. (2012) Proteomic Approach Reveals FKBP4 and S100A9 as Potential Prediction Markers of Therapeutic Response to Neoadjuvant Chemotherapy in Patients with Breast Cancer. Journal of Proteome Research, 11, 1078-1088. https://doi.org/10.1021/pr2008187

[111] Vahora, H., Khan, M.A., Alalami, U. and Hussain, A. (2016) The Potential Role of Nitric Oxide in Halting Cancer Progression through Chemoprevention. Journal of Cancer Prevention, 21, 1-12. https://doi.org/10.15430/JCP.2016.21.1.1

[112] Choudhari, S.K., Chaudhary, M., Bagde, S., Gadbail, A.R. and Joshi, V. (2013) Nitric Oxide and Cancer: A Review. World Journal of Surgical Oncology, 11, 118. https://doi.org/10.1186/1477-7819-11-118

[113] MacLauchlan, S., Yu, J., Parrish, M., Asoulin, T.A., Schleicher, M. and Krady, M.M. (2011) Endothelial Nitric Oxide Synthase Controls the Expression of the Angiogenesis Inhibitor Thrombospondin 2. Proceedings of the National Academy of Sciences of the United States of America, 108, E1137-E1145. https://doi.org/10.1073/pnas.1104357108 
[114] Chang, C.F., Diers, A.R. and Hogg, N. (2015) Cancer Cell Metabolism and the Modulating Effects of Nitric Oxide. Free Radical Biology \& Medicine, 79, 324-336. https://doi.org/10.1016/j.freeradbiomed.2014.11.012

[115] Rashad, Y.A., Elkhodary, T.R., El-Gayar, A.M. and Eissa, L.A. (2013) Evaluation of Serum Levels of HER2, MMP-9, Nitric Oxide, and Total Antioxidant Capacity in Egyptian Breast Cancer Patients: Correlation with Clinico-Pathological Parameters. Scientia Pharmaceutica, 82, 129-145. https://doi.org/10.3797/scipharm.1306-18

[116] Xiao, X., Li, B.X., Mitton, B., Ikeda, A. and Sakamoto, K.M. (2010) Targeting CREB for Cancer Therapy: Friend or Foe. Current Cancer Drug Targets, 10, 384-391. https://doi.org/10.2174/156800910791208535

[117] Alda, M., Shao, L., Wang, J.F., et al. (2013) Alterations in Phosphorylated cAMP Response Element-Binding Protein (pCREB) Signaling: An Endopheno-Type of Lithium-Responsive Bipolar Disorder? Bipolar Disorders, 15, 824-831.

https://doi.org/10.1111/bdi.12131

[118] Molnar, P., Perraulft, R., Louis, S. and Zahradka, P. (2014) The Cyclic AMP Response Element-Binding Protein (CREB) Mediates Smooth Muscle Cell Proliferation in Response to Angiotensin II. Journal of Cell Communication and Signaling, 8, 29-37. https://doi.org/10.1007/s12079-013-0215-5

[119] Huang, S., Ren, Y., Wang, P., et al. (2015) Transcription Factor CRED in Involved in CaSR-Mediated Cytoskeleton Gene Expression. The Anatomical Record, 298, 501-512. https://doi.org/10.1002/ar.23089

[120] Li, X., Han, X., Llano, J., et al. (2011) Mammalian Target of Rapamycin Inhibition in Macrophages of Asymptomatic HIV+ Persons Reverses the Decrease in TLR-4-Mediated TNF- $\alpha$ Release through Prolongation of MAPK Pathway Activation. The Journal of Immunology, 187, 6052-6058.

https://doi.org/10.4049/jimmunol.1101532

[121] Afonyushkin, T., Oskolkova, O.V., Philippova, M., et al. (2010) Oxidized Phospholipids Regulate Expression of ATF4 and VEGF in Endothelial Cells via NRF2-Dependent Mechanism: Novel Point of Convergence between Electrophilic and Unfolded Protein Stress Pathways. Arteriosclerosis, Thrombosis, and Vascular Biology, 30, 1007-1013. https://doi.org/10.1161/ATVBAHA.110.204354

[122] Son, J., Lee. J.H., Kim, H.N., Ha, H. and Lee, Z.H. (2010) cAMP-Response Element-Binding Protein Positively Regulates Breast Cancer Metastasis and Subsequent Bone Destruction. Biochemical and Biophysical Research Communications, 398, 309-314. https://doi.org/10.1016/j.bbrc.2010.06.087

[123] Fan, C.F., Mao, X.Y. and Wang, E.H. (2012) Elevated p-CREB-2 (ser 245) Expression Is Potentially Associated with Carcinogenesis and Development of Breast Carcinoma. Molecular Medicine Reports, 5, 357-362.

[124] Singh, R., Shankar, B.S. and Sainis, K.B. (2014) TGF- $\beta 1$-ROS-ATM-CREB Signaling Axis in Macrophage Mediated Migration of Human Breast Cancer MCF7 Cells. Cell Signal, 26, 1604-1615. https://doi.org/10.1016/j.cellsig.2014.03.028

[125] Steven, A., Leisz, S., Massa, C., et al. (2013) HER-2/Neu Mediates Oncogenic Transformation via Altered CREB Expression and Function. Molecular Cancer Research, 11, 1462-1477. https://doi.org/10.1158/1541-7786.MCR-13-0125

[126] Saldanha, C.J., Remage-Healey, L. and Schlinger, B.A. (2011) Synaptocrine Signaling: Steroid Synthesis and Action at the Synapse. Endocrine Reviews, 32, 532-549. https://doi.org/10.1210/er.2011-0004

[127] Aka, J.A., Zerradi, M., Houle, F., Huot, J. and Lin, S.X. (2012) 17 $\beta$-Hydroxysteroid Dehydrogenase Type 1 Modulates Breast Cancer Protein Profile and Impacts Cell 
Migration. Breast Cancer Research, 13, R92. https://doi.org/10.1186/bcr3207

[128] Russo, J., Fernandez, S.V., Russo, P.A., Fernbaugh, R., Sheriff, F.S., Lareef, H.M., Garber, J. and Russo, I.H. (2006) 7-Beta-Estradiol Induces Transformation and Tumorigenesis in Human Breast Epithelial Cells. The FASEB Journal, 20, 1622-1634. https://doi.org/10.1096/fj.05-5399com

[129] Jordan, V.C. and Ford, L.G. (2011) Paradoxical Clinical Effect of Estrogen on Breast Cancer Risk: A "New" Biology of Estrogen-Induced Apoptosis. Cancer Prevention Research, 4, 633-637. https://doi.org/10.1158/1940-6207.CAPR-11-0185

[130] Zheng, S., Huang, J., Zhou, K., Zhang, C., Xiang, Q., Tan, Z., Wang, T. and Fu, X. (2011) $17 \beta$-Estradiol Enhances Breast Cancer Cell Motility and Invasion via Extranuclear Activation of Actin-Binding Protein Ezrin. PLoS ONE, 6, e22439.

https://doi.org/10.1371/journal.pone.0022439

[131] Pattarozzi, A., Gatti, M., Barbieri, F., Wurth, R., Porcile, C., Lunardi, G., Ratto, A., Favoni, R., Bajetto, A., Ferrari, A., et al. (2008) 17beta-Estradiol Promotes Breast Cancer Cell Proliferation-Inducing Stromal Cell-Derived Factor-1-Mediated Epidermal Growth Factor Receptor Transactivation: Reversal by Gefitinib Pretreatment. Molecular Pharmacology, 73, 191-202. https://doi.org/10.1124/mol.107.039974

[132] Loffek, S., Schilling, O. and Franzke, C.W. (2011) Biological Role of Matrix Metalloproteinases: A Critical Balance. The European Respiratory Journal, 38, 191-208. https://doi.org/10.1183/09031936.00146510

[133] Nagase, H., Visse, R. and Murphy, G. (2006) Structure and Function of Matrix Metalloproteinases and TIMPs. Cardiovascular Research, 69, 562-573. https://doi.org/10.1016/j.cardiores.2005.12.002

[134] Lu, P., Takai, K., Weaver, V.M. and Werb, Z. (2011) Extracellular Matrix Degradation and Remodeling in Development and Disease. Cold Spring Harbor Perspectives in Biology, 3, a005058. https://doi.org/10.1101/cshperspect.a005058

[135] Tallant, C., Marrero, A. and Gomis-Ruth, F.X. (2010) Matrix Metalloproteinases: Fold and Function of Their Catalytic Domains. BBA Molecular Cell Research, 1803, 20-28. https://doi.org/10.1016/j.bbamcr.2009.04.003

[136] Benson, C.S., Babu, S.D., Radhakrishna, S., Selvamurugan, N. and Sankar, B.R. (2013) Expression of Matrix Metalloproteinases in Human Breast Cancer Tissues. Disease Markers, 34, 395-405. https://doi.org/10.1155/2013/420914

[137] Rizwan, A., Cheng, M., Bhujwalla, Z.M., Jiang, L. and Glunde, K. (2015) Breast Cancer Cell Adhesome and Degradome Interact to Drive Metastasis. NPJ Breast Cancer, 1, Article No. 15017. https://doi.org/10.1038/npjbcancer.2015.17

[138] Gialeli, C., Theocharis, A.D. and Karamanos, N.K. (2011) Roles of Matrix Metallo-Proteinases in Cancer Progression and Their Pharmacological Targeting. The FEBS Journal, 278, 16-27. https://doi.org/10.1111/j.1742-4658.2010.07919.x

[139] Koujan, S.E., Gargarib, B.P., Pirouzpanah, S. and Khalili, M. (2015) Matrix Metalloproteinases and Breast Cancer. Thrita, 4, e21959.

[140] Liu, H., Kato, Y., Erzinger, S.A., et al. (2012) The Role of MMP-1 in Breast Cancer Growth and Metastasis to the Brain in a Xenograft Model. BMC Cancer, 12, 583. https://doi.org/10.1186/1471-2407-12-583

[141] Zhang, L., Sullivan, P., Suyama, J. and Marchetti, D. (2010) Epidermal Growth Factor-Induced Heparanase Nucleolar Localization Augments DNA Topoisomerase I Activity in Brain Metastatic Breast Cancer. Molecular Cancer Research, 8, 278-290. https://doi.org/10.1158/1541-7786.MCR-09-0375 
[142] Ring, H., Mendu, S.K., Shirazi-Fard, S., Birnir, B. and Hallbook, F. (2012) GABA Maintains the Proliferation of Progenitors in the Developing Chick Ciliary Marginal Zone and Non-Pigmented Ciliary Epithelium. PLoS ONE, 7, e36874. https://doi.org/10.1371/journal.pone.0036874

[143] Soltani, N., Qiu, H., Aleksic, M., Glinka, Y., Zhao, F., Liu, R., Li, Y., Zhang, N., Chakrabarti, R. and Ng, T. (2011) GABA Exerts Protective and Regenerative Effects on Islet Beta Cells and Reverses Diabetes. Proceedings of the National Academy of Sciences of the United States of America, 108, 11692-11697.

https://doi.org/10.1073/pnas.1102715108

[144] Li, Y.H., Liu, Y., Li, Y.D., Liu, Y.H., Li, F., Ju, Q., Xie, P.L. and Li, G.C. (2012) GABA Stimulates Human Hepatocellular Carcinoma Growth through Overexpressed GABAA Receptor Theta Subunit. World Journal of Gastroenterology, 18, 2704-2711. https://doi.org/10.3748/wjg.v18.i21.2704

[145] Andang, M., Hjerling-Leffler, J., Moliner, A., Lundgren, T.K., Castelo-Branco, G., Nanou, E., Pozas, E., Bryja, V., Halliez, S. and Nishimaru, H. (2008) Histone H2AX-Dependent GABA(A) Receptor Regulation of Stem Cell Proliferation. Nature, 451, 460-464. https://doi.org/10.1038/nature06488

[146] Chen, Z.A., Bao, M.Y., Xu, Y.F., Zha, R.P., Shi, H.B., Chen, T.Y. and He, X.H. (2012) Suppression of Human Liver Cancer Cell Migration and Invasion via the GABAA Receptor. Cancer Biology \& Medicine, 9, 90-98.

[147] Wu, W. (2014) Abstract 3309: Castration-Resistant Prostate Cancer (CRPC) Growth Is Mediated through Gama-Aminobutyric Acid a Receptor (GABAAR). Cancer Research, 74, 3309. https://doi.org/10.1158/1538-7445.AM2014-3309

[148] Zhang, D., Li, X., Yao, Z., Wei, C., Ning, N. and Li, J. (2014) GABAergic Signaling Facilitates Breast Cancer Metastasis by Promoting ERK1/2-Dependent Phosphorylation. Cancer Letters, 348, 100-108. https://doi.org/10.1016/j.canlet.2014.03.006

[149] Bortsov, A.V., Millikan, R.C., Belfer, I., Boortz-Marx, R.L., Arora, H. and McLean, S.A. (2012) $\mu$-Opioid Receptor Gene A118G Polymorphism Predicts Survival in Patients with Breast Cancer. Anesthesiology, 116, 896-902. https://doi.org/10.1097/ALN.0b013e31824b96a1

[150] Cieslinska, A., Sienkiewicz-Szlapka, E., Kostyra, E., et al. (2015) $\mu$-Opioid Receptor Gene (OPRM1) Polymorphism in Patients with Breast Cancer. Tumour Biology, 36, 4655-4660. https://doi.org/10.1007/s13277-015-3113-Z

[151] Singleton, P.A., Mirzapoiazova, T., Hasina, R., Salgia, R. and Moss, J. (2014) Increased $\mu$-Opioid Receptor Expression in Metastatic Lung Cancer. British Journal of Anaesthesia, 113, i103-i108. https://doi.org/10.1093/bja/aeu165

[152] Roy, S., Ninkovic, J., Banerjee, S., Charboneau, R.G., Das, S., Dutta, R., Kirchner, V.A., Koodie, L., Ma, J., Meng, J. and Barke, R.A. (2011) Opioid Drug Abuse and Modulation of Immune Function: Consequences in the Susceptibility to Opportunistic Infections. Journal of NeuroImmune Pharmacology, 6, 442-465. https://doi.org/10.1007/s11481-011-9292-5

[153] Cata, J.P., Bugada, D., Marchesini, M., Gregori, M.D. and Allegri, M. (2016) Opioids and Cancer Recurrence: A Brief Review of the Literature. Cancer Cell \& Microenvironment, 3, e1159.

[154] Merkle, D. and Hoffmann, R. (2011) Roles of cAMP and cAMP-Dependent Protein Kinase in the Progression of Prostate Cancer: Cross-Talk with the Androgen Receptor. Cell Signal, 23, 507-515. https://doi.org/10.1016/j.cellsig.2010.08.017

[155] El-Mowafy, A.M. and Alkhalaf, M. (2003) Resveratrol Activates Adenylyl-Cyclase in 
Human Breast Cancer Cells: A Novel, Estrogen Receptor-Independent Cytostatic Mechanism. Carcinogenesis, 24, 869-873. https://doi.org/10.1093/carcin/bgg015

[156] Pisanti, S., Malfitano, A.M., Grimaldi, C., Santoro, A., Gazzerro, P., Laezza, C., et al. (2009) Use of Cannabinoid Receptor Agonists in Cancer Therapy as Palliative and Curative Agents. Best Practice \& Research: Clinical Endocrinology \& Metabolism, 23, 117-131. https://doi.org/10.1016/j.beem.2009.02.001

[157] Gu, Y., Chen, T., Lopez, E., Wu, W., Wang, X., Cao, J. and Teng, L. (2014) The Therapeutic Target of Estrogen Receptor-alpha36 in Estrogen-Dependent Tumors. Journal of Translational Medicine, 12, 16. https://doi.org/10.1186/1479-5876-12-16

[158] Levin, E.R. (2012) Elusive Extranuclear Estrogen Receptors in Breast Cancer. Clinical Cancer Research, 18, 6-8. https://doi.org/10.1158/1078-0432.CCR-11-2547

[159] Maggiolini, M. and Picard, D. (2010) The Unfolding Stories of GPR30, a New Membrane-Bound Estrogen Receptor. Journal of Endocrinology, 204, 105-114. https://doi.org/10.1677/JOE-09-0242

[160] Chambliss, K.L., Wu, Q., Oltmann, S., et al. (2010) Non-Nuclear Estrogen Receptor Alpha Signaling Promotes Cardiovascular Protection But Not Uterine or Breast Cancer Growth in Mice. Journal of Clinical Investigation, 120, 2319-2330. https://doi.org/10.1172/JCI38291

[161] Pelekanou, V., Notas, G., Kampa, M., Tsentelierou, E., Radojicic, J., Leclercq, G., Castanas, E. and Stathopoulos, E.N. (2012) ERa36, a New Variant of the ER $\alpha$ Is Expressed in Triple Negative Breast Carcinomas and Has a Specific Transcriptomic Signature in Breast Cancer Cell Lines. Steroids, 77, 928-934. https://doi.org/10.1016/j.steroids.2011.12.016

[162] Ariazi, E.A., Brailoiu, E., Yerrum, S., et al. (2010) The G Protein-Coupled Receptor GPR30 Inhibits Proliferation of Estrogen Receptor-Positive Breast Cancer Cells. Cancer Research, 70, 1184-1194. https://doi.org/10.1158/0008-5472.CAN-09-3068

[163] Zhang, X., Kang, L., Ding, L., Vranic, S., Gatalica, Z. and Wang, Z.-Y. (2011) A Positive Feedback Loop of ER- $\alpha 36 /$ EGFR Promotes Malignant Growth of ER-Negative Breast Cancer Cells. Oncogene, 30, 770-780. https://doi.org/10.1038/onc.2010.458

[164] Wei, W., Chen, Z.-J., Zhang, K.-S., et al. (2014) The Activation of G Protein-Coupled Receptor 30 (GPR30) Inhibits Proliferation of Estrogen Receptor-Negative Breast Cancer Cells in Vitro and in Vivo. Cell Death \& Disease, 5, e1428. https://doi.org/10.1038/cddis.2014.398

[165] Weißenborn, C., Ignatov, T., Ochel, H.J., et al. (2014) GPER Functions as a Tumor Suppressor in Triple-Negative Breast Cancer Cells. Journal of Cancer Research and Clinical Oncology, 140, 713-723. https://doi.org/10.1007/s00432-014-1620-8

[166] Wang, D., Hu, L., Zhang, G., Zhang, L. and Chen, C. (2010) G Protein-Couples Receptor 30 in Tumor Development. Endocrine, 38, 29-37. https://doi.org/10.1007/s12020-010-9363-Z

[167] Lappano, R., Santolla, M.F., Pupo, M., et al. (2012) MIBE Acts as Antagonist Ligand of Both Estrogen Receptor $\alpha$ and GPER in Breast Cancer Cells. Breast Cancer Research, 14, R12. https://doi.org/10.1186/bcr3096

[168] Ignatov, A., Ignatov, T., Roessner, A., Costa, S.D. and Kalinski, T. (2010) Role of GPR30 in the Mechanisms of Tamoxifen Resistance in Breast Cancer MCF-7 Cells. Breast Cancer Research and Treatment, 123, 87-96. https://doi.org/10.1007/s10549-009-0624-6

[169] Lemmon, M.A. and Schlessinger, J. (2010) Cell Signaling by Receptor Tyrosine Kinases. Cell, 141, 1117-1134. https://doi.org/10.1016/j.cell.2010.06.011 
[170] Oku, S., van der Meulen, T., Copp, J., Glenn, G. and van der Geer, P. (2012) Engineering NGF Receptors to Bind Grb2 Directly Uncovers Differences in Signaling Ability between Grb2- and ShcA-Binding Sites. FEBS Letters, 586, 3658-3664. https://doi.org/10.1016/j.febslet.2012.08.021

[171] Lucs, A.V., Muller, W.J. and Muthuswamy, S.K. (2010) Shc Is Required for ErbB2-Induced Inhibition of Apoptosis But Is Dispensable for Cell Proliferation and Disruption of Cell Polarity. Oncogene, 29, 174-187.

https://doi.org/10.1038/onc.2009.312

[172] Wills, M.K. and Jones, N. (2012) Teaching an Old Dogma New Tricks: Twenty Years of Shc Adaptor Signalling. Biochemical Journal, 447, 1-16. https://doi.org/10.1042/BJ20120769

[173] Zheng, Y., Zhang, C., Croucher, D.R., Soliman, M.A., St-Denis, N., Pasculescu, A., Taylor, L., Tate, S.A., Hardy, W.R., Colwill, K., Dai, A.Y., Bagshaw, R., Dennis, J.W., Gingras, A.C., Daly, R.J. and Pawson, T. (2013) Temporal Regulation of EGF Signalling Networks by the Scaffold Protein Shc1. Nature, 499, 166-171. https://doi.org/10.1038/nature12308

[174] Northey, J.J., Dong, Z., Ngan, E., Kaplan, A., Hardy, W.R., Pawson, T. and Siegel, P.M. (2013) Distinct Phosphotyrosine-Dependent Functions of the ShcA Adaptor Protein Are Required for Transforming Growth Factor Beta (TGFbeta)-Induced Breast Cancer Cell Migration, Invasion, and Metastasis. The Journal of Biological Chemistry, 288, 5210-5222. https://doi.org/10.1074/jbc.M112.424804

[175] Rajendran, M., Thomes, P., Zhang, L., Veeramani, S. and Lin, M.-F. (2010) p66Shc-A Longevity Redox Protein in Human Prostate Cancer Progression and Metastasis: p66Shc in Cancer Progression and Metastasis. Cancer and Metastasis Reviews, 29, 207-222. https://doi.org/10.1007/s10555-010-9213-8

[176] Ma, Z., Liu, Z., Wu, R.-F. and Terada, L. (2010) p66Shc Restrains Ras Hyperactivation and Suppresses Metastatic Behavior. Oncogene, 29, 5559-5567. https://doi.org/10.1038/onc.2010.326

[177] Hudson, J., Ha, J.R., Sabourin, V., et al. (2014) p66ShcA Promotes Breast Cancer Plasticity by Inducing an Epithelial-to-Mesenchymal Transition. Molecular and Cellular Biology, 34, 3689-3701. https://doi.org/10.1128/MCB.00341-14

[178] Haines, E., Saucier, C. and Claing, A. (2014) The Adaptor Proteins p66Shc and Grb2 Regulate the Activation of the GTPases ARF1 and ARF6 in Invasive Breast Cancer Cells. The Journal of Biological Chemistry, 289, 5687-5703. https://doi.org/10.1074/jbc.M113.516047

[179] Sassone-Corsi, P. (2012) The Cyclic AMP Pathway. Cold Spring Harbor Perspectives in Biology, 4, a011148. https://doi.org/10.1101/cshperspect.a011148

[180] Lee, L.C., Maurice, D.H. and Baillie, G.S. (2013) Targeting Protein-Protein Interactions within the Cyclic AMP Signaling System as a Therapeutic Strategy for Cardiovascular Disease. Future Medicinal Chemistry, 5, 451-464. https://doi.org/10.4155/fmc.12.216

[181] Fajardo, A.M., Piazza, G.A. and Tinsley, H.N. (2014) The Role of Cyclic Nucleotide Signaling Pathways in Cancer: Targets for Prevention and Treatment. Cancers, 6, 436-458. https://doi.org/10.3390/cancers6010436

[182] Follin-Arbelet, V., Hofgaard, P.O., Hauglin, H., et al. (2011) Cyclic AMP Induces Apoptosis in Multiple Myeloma Cells and Inhibits Tumor Development in a Mouse Myeloma Model. BMC Cancer, 11, 301. https://doi.org/10.1186/1471-2407-11-301

[183] Dong, H., Claffey, K.P., Brocke, S. and Epstein, P.M. (2015) Inhibition of Breast Cancer Cell Migration by Activation of cAMP Signaling. Breast Cancer Research 
and Treatment, 152, 17-28. https://doi.org/10.1007/s10549-015-3445-9

[184] Pon, C.K., Lane, J.R., Sloan, E.K. and Halls, M.L. (2016) The $\beta 2$-Adrenoceptor Activates a Positive cAMP-Calcium Feedforward Loop to Drive Breast Cancer Cell Invasion. The FASEB Journal, 30, 1144-1154. https://doi.org/10.1096/fj.15-277798

[185] Vanhaesebroeck, B., Vogt, P.K. and Rommel, C. (2011) PI3K-From the Bench to the Clinic and Back. Current Topics in Microbiology and Immunology, 347, 1-19.

[186] Baselga, J. (2011) Targeting the Phosphoinositide-3 (PI3) Kinase Pathway in Breast Cancer. The Oncologist, 16, 12-19. https://doi.org/10.1634/theoncologist.2011-S1-12

[187] Loi, S., Haibe-Kains, B., Majjaj, S., et al. (2010) PIK3CA Mutations Associated with Gene Signature of Low mTORC1 Signaling and Better Outcomes in Estrogen Receptor-Positive Breast Cancer. Proceedings of the National Academy of Sciences of the United States of America, 107, 10208-10213. https://doi.org/10.1073/pnas.0907011107

[188] Baselga, J., Semiglazov, V., van Dam, P., et al. (2009) Phase II Randomized Study of Neoadjuvant Everolimus plus Letrozole Compared with Placebo plus Letrozole in Patients with Estrogen Receptor-Positive Breast Cancer. Journal of Clinical Oncology, 27, 2630-2637. https://doi.org/10.1200/JCO.2008.18.8391

[189] Ellis, M.J., Lin, L., Crowder, R., Tao, Y., et al. (2010) Phosphatidyl-Inositol-3-Kinase Alpha Catalytic Subunit Mutation and Response to Neoadjuvant Endocrine Therapy for Estrogen Receptor Positive Breast Cancer. Breast Cancer Research and Treatment, 119, 379-390. https://doi.org/10.1007/s10549-009-0575-y

[190] Perez-Tenorio, G., Alkhori, L., Olsson, B., et al. (2007) PIK3CA Mutations and PTEN Loss Correlate with Similar Prognostic Factors and Are Not Mutually Exclusive in Breast Cancer. Clinical Cancer Research, 13, 3577-3584. https://doi.org/10.1158/1078-0432.CCR-06-1609

[191] Miller, T.W., Rexer, B.N., Garrett, J.T. and Arteaga, C.L. (2011) Mutations in the Phosphatidylinositol 3-Kinase Pathway: Role in Tumor Progression and Therapeutic Implications in Breast Cancer. Breast Cancer Research, 13, 224. https://doi.org/10.1186/bcr3039

[192] Castaneda, C.A., Lopez-Ilasaca, M., Pinto, J.A., et al. (2014) PIK3CA Mutations in Peruvian Patients with HER2-Amplified and Triple Negative Non-Metastatic Breast Cancers. Hematology/ Oncology and Stem Cell Therapy, 7, 142-148. https://doi.org/10.1016/j.hemonc.2014.09.007

[193] Juric, D. and Baselga, J. (2012) Tumor Genetic Testing for Patient Selection in Phase I Clinical Trials: The Case of PI3K Inhibitors. Journal of Clinical Oncology, 30, 765-766. https://doi.org/10.1200/JCO.2011.39.6390

[194] Urtreger, A.J., Kazanietz, M.G. and Bal de Kier Joffe, E.D. (2012) Contribution of Individual PKC Isoforms to Breast Cancer Progression. IUBMB Life, 64, 18-26. https://doi.org/10.1002/iub.574

[195] Basu, A. and Pal, D. (2010) Two Faces of Protein Kinase Cdelta: The Contrasting Roles of PKCdelta in Cell Survival and Cell Death. The Scientific World Journal, 10, 2272-2284. https://doi.org/10.1100/tsw.2010.214

[196] Luna-Ulloa, L.B., Hernandez-Maqueda, J.G., Castaneda-Patlan, M.C. and Robles-Flores, M. (2011) Protein Kinase C in Wnt Signaling: Implications in Cancer Initiation and Progression. IUBMB Life, 63, 915-921. https://doi.org/10.1002/iub.559

[197] Chen, Z., Forman, L.W., Williams, R.M. and Faller, D.V. (2014) Protein Kinase C- $\delta$ 
Inactivation Inhibits the Proliferation and Survival of Cancer Stem Cells in Culture and in Vivo. BMC Cancer, 14, 90. https://doi.org/10.1186/1471-2407-14-90

[198] Belle, L., Ali, N., Lonic, A., et al. (2015) The Tyrosine Phosphatase PTPN14 (Pez) Inhibits Metastasis by Altering Pteoin Trafficking. Science Signaling, 8, RA18. https://doi.org/10.1126/scisignal.2005547

[199] Lønne, G.K., Cornmark, L., Zahirovic, I.O., Landberg, G., Jirstrom, K. and Larsson, C. (2010) PKC $\alpha$ Expression Is a Marker for Breast Cancer Aggressiveness. Molecular Cancer, 9, 76. https://doi.org/10.1126/scisignal.2005547

[200] Diaz Bessone, M.I., Berardi, D.E., Campodonico, P.B., et al. (2011) Involvement of PKC delta (PKCdelta) in the Resistance against Different Doxorubicin Analogs. Breast Cancer Research Treat, 126, 577-587. https://doi.org/10.1007/s10549-010-0956-2

[201] Allen-Petersen, B.L., Carter, C.J., Ohm, A.M. and Reyland, M.E. (2014) Protein Kinase $\mathrm{C} \delta$ Is Required for ErbB2-Driven Mammary Gland Tumorigenesis and Negatively Correlates with Prognosis in Human Breast Cancer. Oncogene, 33, 1306-1315. https://doi.org/10.1038/onc.2013.59

[202] Zuo, Y., Wu, Y. and Chakraborty, C. (2012) Cdc42 Negatively Regulates Intrinsic Migration of Highly Aggressive Breast Cancer Cells. Journal of Cellular Physiology, 227, 1399-1407. https://doi.org/10.1002/jcp.22853

[203] McKenzie, A.J., Campbell, S.L. and Howe, A.K. (2011) Protein Kinase A Activity and Anchoring Are Required for Ovarian Cancer Cell Migration and Invasion. PLoS ONE, 6, e26552. https://doi.org/10.1371/journal.pone.0026552

[204] Bentin Toaldo, C., Alexi, X., Beelen, K., et al. (2015) Protein Kinase A-Induced Tamoxifen Resistance Is Mediated by Anchoring Protein AKAP13. BMC Cancer, 15, 588. https://doi.org/10.1186/s12885-015-1591-4

[205] Sarwar, M. and Persson, J.L. (2012) The Protein Kinase A (PKA) Intracellular Pathway and Androgen Receptor: A Novel Mechanism Underlying the Castration-Resistant and Metastatic Prostate Cancer. Journal of Cancer Science and Therapy, 4, 1. https://doi.org/10.4172/1948-5956.S5-003

[206] Donini, C.F., Di Zazzo, E., Zuchegna, C., et al. (2012) The p85a Regulatory Subunit of PI3K Mediates cAMP-PKA and Retinoic Acid Biological Effects on MCF-7 Cell Growth and Migration. International Journal of Oncology, 40, 1627-1635.

[207] Mao, L., Yuan, L., Slakey, L.M., Jones, F.E., Burow, M.E. and Hill, S.M. (2010) Inhibition of Breast Cancer Cell Invasion by Melatonin Is Mediated through Regulation of the p38 Mitogen-Activated Protein Kinase Signaling Pathway. Breast Cancer. $B C R, 12, \mathrm{R} 107$. https://doi.org/10.1186/bcr2794

[208] Beristain, A.G., Molyneux, S.D., Joshi, P.A., Pomroy, N.C., Di Grappa, M.A., et al. (2015) PKA Signaling Drives Mammary Tumorigenesis through Src. Oncogene, 34, 1160-1173. https://doi.org/10.1038/onc.2014.41

[209] Liao, X.H., Wang, Y., Wang, N., et al. (2014) Human Chorionic Gonadotropin Decreases Human Breast Cancer Cell Proliferation and Promotes Differentiation. IUBMB Life, 66, 352-360. https://doi.org/10.1002/iub.1269

[210] Yang, Y.R., Choi, J.H., Chang, J.S., et al. (2012) Diverse Cellular and Physiological Roles of Phospholipase C- $\gamma 1$. Advances in Biological Regulation, 52, 138-151. https://doi.org/10.1016/j.advenzreg.2011.09.017

[211] Raimondi, C. and Falasca, M. (2012) Phosphoinositides Signalling in Cancer: Focus on PI3K and PLC. Advances in Biological Regulation, 52, 166-182.

https://doi.org/10.1016/j.advenzreg.2011.09.016 
[212] Kadamur, G. and Ross, E.M. (2013) Mammalian Phospholipase C. Annual Review of Physiology, 75, 127-154. https://doi.org/10.1146/annurev-physiol-030212-183750

[213] Lattanzio, R., Marchisio, M., La Sorda, R., et al. (2013) Overexpression of Activated Phospholipase $\mathrm{C} \gamma 1$ Is a Risk Factor for Distant Metastases in T1-T2, N0 Breast Cancer Patients Undergoing Adjuvant Chemotherapy. International Journal of Cancer, 132, 1022-1031. https://doi.org/10.1002/ijc.27751

[214] Bunney, T.D. and Katan, M. (2011) PLC Regulation: Emerging Pictures for Molecular Mechanisms. Trends in Biochemical Sciences, 36, 88-96. https://doi.org/10.1016/j.tibs.2010.08.003

[215] Balz, L.M., Bartkowiak, K., Andreas, A., et al. (2012) The Interplay of HER2/HER3/PI3K and EGFR/HER2/PLC- $\gamma 1$ Signaling in Breast Cancer Cell Migration and Dissemination. The Journal of Pathology, 227, 234-244.

https://doi.org/10.1002/path.3991

[216] Brugnoli, F., Grassilli, S., Piazzi, M., et al. (2013) In Triple Negative Breast Tumor Cells, PLC- $\beta 2$ Promotes the Conversion of CD133 High to CD133 Low Phenotype and Reduces the CD133-Related Invasiveness. Molecular Cancer, 12, 165. https://doi.org/10.1186/1476-4598-12-165

[217] Marchi, S., Marinello, M., Bononi, A., et al. (2012) Selective Modulation of Subtype III IP3R by Akt Regulates ER Ca ${ }^{2+}$ Release and Apoptosis. Cell Death \& Disease, 3 , e304. https://doi.org/10.1038/cddis.2012.45

[218] Akimzhanov, A.M. and Boehning, D. (2012) IP3R Function in Cells of the Immune System. Wiley Interdisciplinary Reviews. Membrane Transport and Signaling, 1, 329-339. https://doi.org/10.1002/wmts.27

[219] Rudiger, S., Jung, P. and Shuai, J.-W. (2012) Termination of $\mathrm{Ca}^{2+}$ Release for Clustered IP3R Channels. PLoS Computational Biology, 8, e1002485.

https://doi.org/10.1371/journal.pcbi.1002485

[220] Serysheva, I.I. (2014) Toward a High-Resolution Structure of IP3R Channel. Cell Calcium, 56, 125-132. https://doi.org/10.1016/j.ceca.2014.08.002

[221] Szatkowski, C., Parys, J.B., Ouadid-Ahidouch, H. and Matifat, F. (2010) Inositol 1,4,5-Trisphosphate-Induced $\mathrm{Ca}^{2+}$ Signalling Is Involved in Estradiol-Induced Breast Cancer Epithelial Cell Growth. Molecular Cancer, 9, 156.

https://doi.org/10.1186/1476-4598-9-156

[222] Andruska, N., Zheng, X., Yang, X., Helferich, W.G. and Shapiro, D.J. (2015) Anticipatory Estrogen Activation of the Unfolded Protein Response Is Linked to Cell Proliferation and Poor Survival in Estrogen Receptor $\alpha$ Positive Breast Cancer. Oncogene, 34, 3760-3769.

[223] Hedgepeth, S.C., Garcia, M.I., Wagner, L.E., et al. (2015) The BRCA1 Tumor Suppressor Binds to Inositol 1,4,5-Trisphosphate Receptors to Stimulate Apoptotic Calcium Release. The Journal of Biological Chemistry, 290, 7304-7313. https://doi.org/10.1074/jbc.M114.611186

[224] Akl, H. and Bultynck, G. (2013) Altered $\mathrm{Ca}^{2+}$ Signaling in Cancer Cells: Proto-Oncogenes and Tumor Suppressors Targeting IP3 Receptors. Biochimica et Biophysica Acta, 1835, 180-193. https://doi.org/10.1016/j.bbcan.2012.12.001

[225] Prabhu, V. and Guruyayoorappan, C. (2010) Nitric Oxide: Pros and Cons in Tumor Progression. Immunopharmacology and Immunotoxicology, 32, 387-392. https://doi.org/10.3109/08923970903440192

[226] Qian, J. and Fulton, D. (2013) Post-Translational Regulation of Endothelial Nitric Oxide Synthase in Vascular Endothelium. Frontiers in Physiology, 4, 347. 
https://doi.org/10.3389/fphys.2013.00347

[227] Green, D.J. (2009) Exercise Training as Vascular Medicine: Direct Impacts on the Vasculature in Humans. Exercise and Sport Sciences Reviews, 37, 196-202.

[228] Gao, X., Wang, J., Wang, W., Wang, M. and Zhang, J. (2015) eNOS Genetic Polymorphisms and Cancer Risk: A Meta-Analysis and a Case-Control Study of Breast Cancer. Medicine, 94, e972. https://doi.org/10.1097/MD.0000000000000972

[229] Zhang, L., Chen, L.M., Wang, M.N., et al. (2014) The G894t, T-786c and 4b/a Polymorphisms in Enos Gene and Cancer Risk: A Meta-Analysis. Journal of Evidence-Based Medicine, 7, 263-269. https://doi.org/10.1111/jebm.12126

[230] Zintzaras, E., Grammatikou, M., Kitsios, G.D., et al. (2010) Polymorphisms of the Endothelial Nitric Oxide Synthase Gene in Breast Cancer: A Genetic Association Study and Meta-Analysis. Journal of Human Genetics, 55, 743-748. https://doi.org/10.1038/jhg.2010.100

[231] Haque, S., Mandal, R.K. and Akhter, N. (2015) G89RT and 4a/b Polymorphisms of NOS3 Gene Are Not Associated with Cancer Risk: A Meta-Analysis. Asian Pacific Journal of Cancer Prevention, 16, 2929-2937.

https://doi.org/10.7314/APJCP.2015.16.7.2929

[232] Zhang, L., Zeng, M. and Fu, B.M. (2016) Inhibition of Endothelial Nitric Oxide Synthase Decreases Breast Cancer Cell MDA-MB-231 Adhesion to Intact Microvessels under Physiological Flows. American Journal of Physiology-Heart and Circulatory Physiology, 310, H1735-H1747. https://doi.org/10.1152/ajpheart.00109.2016

[233] Liu, B., Fu, L., Zhang, C., et al. (2015) Computational Design, Chemical Synthesis, and Biological Evaluation of a Novel ERK Inhibitor (BL-EI001) with Apoptosis-Inducing Mechanisms in Breast Cancer. Oncotarget, 6, 6762-6775.

[234] Kim, E.K. and Choi, E.J. (2010) Pathological Roles of MAPK Signaling Pathways in Human Diseases. Biochimica et Biophysica Acta, 1802, 396-405. https://doi.org/10.1016/j.bbadis.2009.12.009

[235] Roskoski, R. (2012) ERK1/2 MAP Kinases: Structure, Function, and Regulation. Pharmacological Research, 66, 105-143. https://doi.org/10.1016/j.phrs.2012.04.005

[236] Hong, B., Li, H., Zhang, M., et al. (2015) p38 MAPK Inhibits Breast Cancer Metastasis through Regulation of Stromal Expansion. International Journal of Cancer, 136, 34-43. https://doi.org/10.1002/ijc.28958

[237] Ventura, C., Venturino, A., Miret, N., et al. (2015) Chlorpyrifos Inhibits Cell Proliferation through ERK1/2 Phosphorylation in Breast Cancer Cell Lines. Chemosphere, 120, 343-350. https://doi.org/10.1016/j.chemosphere.2014.07.088

[238] Laprevotte, E., Bastid, J., Cochaud, S., et al. (2015) Abstract 5027: Interleukin-17B Promotes Chemoresistance of Breast Tumor through ERK1/2 Anti-Apoptotic Pathway. Proceedings: AACR 106 th Annual Meeting, 75, 18-22. https://doi.org/10.1158/1538-7445.AM2015-5027

[239] Boston, S.R., Deshmukh, R., Strome, S., Priyakumar, U.D., MacKerell, A.D. and Shapiro, P. (2011) Characterization of ERK Docking Domain Inhibitors That Induce Apoptosis by Targeting Rsk-1 and Caspase-9. BMC Cancer, 11, 7. https://doi.org/10.1186/1471-2407-11-7

[240] Kharman-Biz, A., Gao, H., Ghiasvand, R., Zhao, C., Zendehdel, K. and Dahlman-Wright, K. (2013) Expression of Activator Protein-1 (AP-1) Family Members in Breast Cancer. BMC Cancer, 13, 441. https://doi.org/10.1186/1471-2407-13-441

[241] Lopez-Bergami, P., Lau, E. and Ronai, Z. (2010) Emerging Roles of ATF2 and the 
Dynamic AP1 Network in Cancer. Nature Reviews Cancer, 10, 65-76. https://doi.org/10.1038/nrc2681

[242] Ueno, T., Utsumi, J., Toi, M. and Shimizu, K. (2015) Characteristic Gene Expression Profiles of Human Fibroblasts and Breast Cancer Cells in a Newly Developed Bilateral Coculture System. BioMed Research International, 2015, Article ID: 960840. https://doi.org/10.1155/2015/960840

[243] Dahlman-Wright, K., Qiao, Y., Jonsson, P., Gustafsson, J.A., Williams, C. and Zhao, C. (2012) Interplay between AP-1 and Estrogen Receptor $\alpha$ Regulating Gene Expression and Proliferation Networks in Breast Cancer Cells. Carcinogenesis, 33, 1684-1691. https://doi.org/10.1093/carcin/bgs223

[244] Belguise, K., Milord, S., Galtier, F., Moquet-Torcy, G., Piechaczyk, M. and Chalbos, D. (2012) The PKC $\theta$ Pathway Participates in the Aberrant Accumulation of Fra-1 Protein in Invasive ER-Negative Breast Cancer Cells. Oncogene, 31, 4889-4897. https://doi.org/10.1038/onc.2011.659

[245] Logullo, A.F., Stiepcich, M.M.A., de Toledo Osorio, C.A.B., et al. (2011) Role of Fos-Related Antigen 1 in the Progression and Prognosis of Ductal Breast Carcinoma. Histopathology, 58, 617-625. https://doi.org/10.1111/j.1365-2559.2011.03785.x

[246] Scroder, C., Schumacher, U., Muller, V., et al. (2010) The Transcription Factor Fra-2 Promotes Mammary Tumour Progression by Changing the Adhesive Properties of Breast Cancer Cells. European Journal of Cancer, 46, 1650-1660. https://doi.org/10.1016/j.ejca.2010.02.008

[247] Jiao, X., Katiyar, S., Willmarth, N.E., et al. (2010) c-Jun Induces Mammary Epithelial Cellular Invasion and Breast Cancer Stem Cell Expansion. The Journal of Biological Chemistry, 285, 8218-8226. https://doi.org/10.1074/jbc.M110.100792

[248] Gao, C., Weisman, D., Gou, N., Ilyin, V. and Gu, A.Z. (2012) Analyzing High Dimensional Toxicogenomic Data Using Consensus Clustering. Environmental Science \& Technology, 46, 8413-8421. https://doi.org/10.1021/es3000454 